\title{
Random Earnings Differences, Lifetime Liquidity Constraints, and Altruistic Intergenerational Transfers*
}

\author{
JOHN LAITNER \\ Economics Department, The University of Michigan, \\ Lorch Hall, Ann Arbor, Michigan 48109
}

Received October 19, 1990; revised March 24, 1992

\begin{abstract}
This paper develops a model of private savings behavior in which households care about their descendants, cannot have negative net worth, and have lifetime earnings depending on random draws from an exogenous distribution of abilities. The elements interact: very lucky parents are likely to leave large estates; constrained children are unusually likely to receive intergenerational transfers. The paper proves the existence of a stationary cross-sectional distribution of wealth, endogenously determines where liquidity constraints will bind, and shows that the long-term interest rate must be such that Ricardian neutrality fails. Its last section generates several illustrative numerical simulations. Journal of Economic Literature Classification Numbers: D90, D91, E21, C68. (C) 1992 Academic Press, Inc.
\end{abstract}

This paper studies a model of private-sector wealth accumulation. The emphasis is long run-the analysis only considers steady-state equilibria. The model's economy has overlapping generations of households. Each lives $2 \cdot T$ years. Parents pass their second half of life as the households of their adult children live through ages 1 to $T$. Four key elements in the framework are: (1) heterogeneity among households -in the form of random differences in earnings abilities; (2) intergenerational altruism; (3) nonnegativity constraints on households' intergenerational transfers and asset holdings; and (4) technological progress. A priori and in terms of the results below, all seem vital; leaving out any one risks not only omitting its contribution but, also, overlooking interactions among the complete set. This paper presents not only theoretical characterizations but, also, see Section 3, several simulations.

Each household's labor earnings depend on the wage rate per "effective" hour, the economywide state of technology, the household's age, and its individual ability. A variable $Z$ measures the last. Each household's $Z$

* I owe thanks to seminar participants, this journal's referees, and, especially, Andrew Abel for many helpful comments. 
is an independent sampling from a fixed (and exogenous to the model) distribution. A household receives its sampling as it begins its existence (corresponding to the start of adulthood for its man and wife). The sampling is public information and remains fixed for the remainder of the household's life. Earnings' differences interact with altruism: very "lucky" households will want to share with others in their family line through intergenerational transfers; moderately lucky households may leave estates to "insure" against very low $Z$ 's for their progeny.

The altruism of this paper is two-sided: families care both about their descendants and their predecessors. The degree of altruism is strong: families treat their beneficiaries, in a sense described below, as well as themselves. This specification may be viewed as one case of interest-or perhaps as an upper bound on the intensity of altruism one would want to consider. It leads to important gains in tractability in the analysis.

Nonnegativity constraints take two forms. On the one hand, households cannot reach negative net worth. One could think of this borrowing constraint as arising from the institution of bankruptcy laws. On the other hand, parents cannot extort resources from their children (or children from their parents) by choosing to make negative intergenerational transfers-if parents (children) are to receive help from their children (parents), the latter must willingly provide it. As in Altig and Davis [1], Hall [13], and Laitner [23], constraints and altruism operate jointly: the potential liquidity problems of children will tend to induce larger intergenerational transfers from their parents than otherwise; conversely, such transfers will tend to mitigate utility losses from constraints. ${ }^{1}$

Technological change proceeds at a fixed geometric rate. Since it makes future generations generally better off, it will, cet. par., tend to reduce transfers from parents to their descendants.

Two popular existing descriptions of wealth accumulation during equilibrium growth are overlapping generations models and models with intergenerational altruism. In the first, as in this paper, household's have finite lives. The shapes of lifetime profiles of family composition and effective labor supply are important determinants of wealth and factor prices. There may or may not be nonnegativity restrictions on family asset holdings at each age, although the structure of the OLG model requires, at minimum, one such constraint-at the end of life. Fiscal policy is potentially important: the timing of lump-sum taxes vis-à-vis the life cycle, government debt, and social security can affect the economy's steady-state interest rate.

A potential difficulty with the OLG framework is that it seems to have trouble generating equilibria with realistic ratios of wealth-to-output-see,

\footnotetext{
${ }^{1}$ Laitner [23] covers this last topic in some detail.
} 
for example, Auerbach and Kotlikoff [2, Chap. 11] and Mariger [26, Chap. 11]. Kotlikoff and Summers' [18] empirical findings seem to point to the same phenomenon. While the model of this paper has a number of implications in common with conventional OLG formulations, it has no difficulty explaining large amounts of wealth (see Proposition 3 below).

A second approach studies utility maximization over very long or infinite time horizons. One view is that such a formulation approximates, if the subjective discount rate is near zero, a finite life span problem with random shocks occurring extremely frequently (see, for example, Bewley [6]); a second view depicts altruistic families who are concerned about their descendants (see, for example, Barro [3]). This paper's framework clearly has the latter interpretation: families care about their dynasty's well-being as well as about events in their own lifetime.

Within the second approach, one strand of existing literature examines "permanent income" models with random earnings' changes through time. In terms of contrast, in the present work private behavior compels a steady-state interest rate below households' subjective discount ratewhereas Yaari [38], Schechtman [31], and Bewley [6] study behavior at that level. Unlike Yaari [38], this paper incorporates year-by-year nonnegativity constraints on each household's net worth. As in the present paper, Yaari, Schechtman, and Bewley assume that adverse selection and moral hazard preclude insurance against earnings' unevenness and that randomness is idiosyncratic across dynasties (so that the overall rate of interest is nonstochastic).

A second strand of the existing literature on long horizon problems studies representative agent models. Interpreting the Brock and Mirman [7] model, for example, in this manner, Inada conditions on total production will tend to ensure that liquidity constraints on the representative agent never bind. Ricardian debt neutrality follows. In this paper's analysis, on the other hand, some families in each cross section end up being constrained. In fact, this paper's model generates a distribution across dynasties of times until liquidity constraints next bind. Also, in contrast to Brock and Mirman, the model's underlying OLG structure makes each dynasty's earnings and savings behavior dependent on where it is in its life cycle.

Laitner [20,21] and Loury [25] examine intergenerational models with heterogeneity. Laitner $[20,21]$ both assume a lower degree of altruism than the present paper; perhaps more importantly, neither allows lifetime liquidity constraints and lives of more than two periods. In common with this paper, Loury generates a distribution of wealth from ability differences; in contrast, his concern centers on human capital and there are no economywide factor markets.

This paper's organization is as follows. Section 1 sets up an overlapping 
generations framework with altruism. It then introduces earnings heterogeneity and provides existence theorems and characterizations. Section 2 contributes several additional theoretical results. Section 3 presents preliminary numerical simulations, and Section 4 concludes the paper.

\section{The Framework}

This section presents this paper's basic framework. Private-sector wealth accumulation is the focus of attention. Overall, the economy has an aggregate production function in which capital and "effective" labor yield a single output. The latter is homogeneously divisible into investment and consumption. Its current price is always 1 . Time is discrete. This paper considers only steady states. The features defining such an equilibrium are: (i) the net-of-tax interest rate $r$ and the net-of-tax wage per "effective" labor unit $w$ are independent of time; (ii) the aggregate "effective" labor supply, $E_{t}$ at time $t$, grows geometrically at the rate of labor-augmenting technological progress $\gamma$, as docs the aggregate wealth stock, $K_{t}$; and, (iii) each agent arranges its consumption and saving to maximize private utility. Assets carried by a family from time $t$ to $t+1$ finance a portion of the aggregate wealth stock at the latter date. The economy is closed and there is no money or government debt; hence, $K_{t+1}$ equals the physical capital stock used in production at time $t+1$.

The first two subsections below present this paper's assumptions about preferences. The next formulates a dynasty's utility-maximization problem. The one after presents mathematical results. The final subsection interprets the results. This paper's appendix supplies proofs for all propositions.

\section{Utility from Lifetime Consumption}

There are an equal and large number of families of every age $s \in\{1, \ldots, 2 \cdot T\}$. An individual household begins with an adult male and female. Over their first $T$ years they raise two children. The children then leave home to form new households. The parent household lives an additional $T$ years, dying just before its children's children become adults and form new families. The overall population is constant. All families have the same preference ordering. Each inelastically supplies natural labor units according to a given formula dependent on its age and ability. Labor augmenting technological progress at rate $\gamma>0$ converts natural labor units into "effective units."

This paper omits the complexities of marital ties among families (see Bernheim and Bagwell [5]). In other words, think of an economy composed of forever separate family lines. For example, among firstgeneration descendant families, suppose parents only care about the one 
including their eldest female child; among second-generation descendant families, again only the one with their eldest female descendant; etc. Laitner [22] shows that such results have a second interpretation incorporating connections through marriage - with choice of marital partner being an endogenous part of the model. (In this alternative interpretation, all children receive symmetric treatment.)

Figure 1 shows a time schematic for one family line. At date $t+1$ the line's inheriting generation- $i$ household is age $T+1$ and its inheriting descendant is age 1 . At time $t+T$, generation $i$ finishes its life and generation $i+1$ attains middle age. One period later (the line's) generation $i+2$ starts.

The subjective discount rate (for all families) is $\delta \geqslant 0$. Define $\Delta \equiv(1+\delta)^{-T}$. Consider the household of generation $i$ in Fig. 1. Let $c_{i}(s)$ be its lifetime consumption at each age $s=1, \ldots, 2 \cdot T$; let $u\left(c_{i}(s), s\right)$ be the corresponding flow of utility; let

$$
\xi_{i}^{1} \equiv\left(c_{i}(1), \ldots, c_{i}(T)\right), \quad \xi_{i}^{2} \equiv\left(c_{i}(T+1), \ldots, c_{i}(2 \cdot T)\right) ;
$$

and let the household's utility from its own lifetime consumption be

$$
\begin{aligned}
U^{1}\left(\xi_{i}^{1}\right)+\Delta \cdot U^{2}\left(\xi_{i}^{2}\right) \equiv & \sum_{s=1}^{T}\left(\frac{1}{1+\delta}\right)^{s} \cdot u\left(c_{i}(s), s\right)+\Delta \\
& \cdot \sum_{s=T+1}^{2 \cdot T}\left(\frac{1}{1+\delta}\right)^{s-T} \cdot u\left(c_{i}(s), s\right) .
\end{aligned}
$$

For the existence of a steady state with technological progress, the analysis below requires homothetic preferences-in other words, isoelastic utility (see Katzner [16, Theorem 2.4-4]): for some function of age $h(s)$,

$$
u(c, s)=h(s) \cdot \frac{1}{\beta} \cdot c^{\beta}, \quad \beta \neq 0, \beta<1, \text { or } u(c, s)=h(s) \cdot \ln (c) .
$$

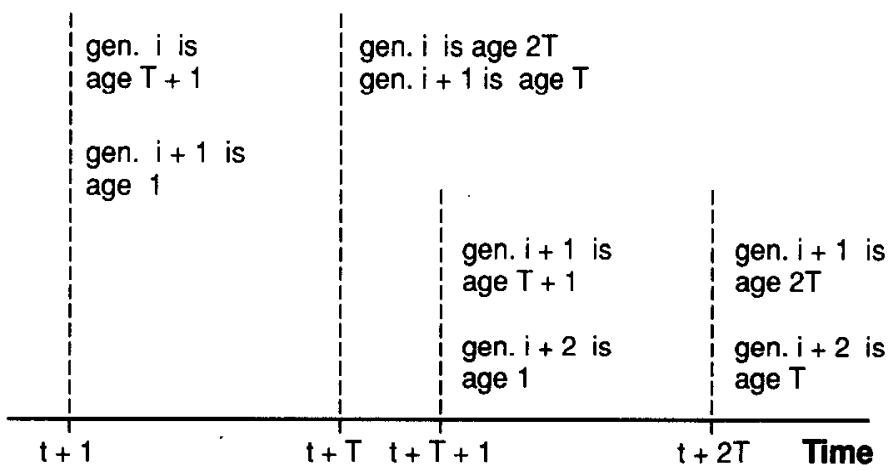

FIG. 1. Overlapping generations for one family line. 
The elasticity of marginal substitution for consumption between time periods is

$$
\sigma \equiv \frac{1}{1-\beta}
$$

For expositional simplicity, omit the separate logarithmic case below. Let $n(s)$ be the number of "equivalent" adults in a household at age $s$-Tobin [34], for example, uses this concept. Given $n(s)$, replace $h(s)$ in (2) with

$$
h(s) \equiv n(s)^{1-\beta} .
$$

\section{Intergenerational Altruism}

Continuing with generation- $i$ from Fig. 1, let its family line's consumption be $\left({ }_{i} \xi, \xi_{i}\right)$,

$$
{ }_{i} \xi \equiv\left(\ldots, \xi_{i-2}^{2}, \xi_{i-1}^{1}, \xi_{i-1}^{2}, \xi_{i}^{1}\right), \quad \xi_{i} \equiv\left(\xi_{i}^{2}, \xi_{i+1}^{1}, \xi_{i+1}^{2}, \ldots\right) .
$$

Then assume the total utility of the generation- $i$ household is

$$
W_{i}\left(\xi_{i}, \xi_{i}\right)=\sum_{i=-\infty}^{\infty} \Delta^{i} \cdot\left[U^{2}\left(\xi_{i}^{2}\right)+U^{1}\left(\xi_{i+1}^{1}\right)\right] .
$$

A consumption path is feasible if it satisfies all budget and liquidity constraints below. Note that at time $t+1$ consumption ${ }_{i} \xi$ is already past. This paper assumes that at that moment the family of generation $i$ wants a feasible $\xi_{i}$ with

$$
W_{i}\left({ }_{i} \xi, \xi_{i}\right)-W_{i}\left({ }_{i} \xi, \xi_{i}^{*}\right) \geqslant 0 \quad \text { all feasible } \xi_{i}^{*},
$$

and, at the same time, generation $i+1$ in the line wants a feasible $\xi_{i}$ with

$$
W_{i+1}\left({ }_{i} \xi, \xi_{i}\right)-W_{i+1}\left({ }_{i} \xi, \xi_{i}^{*}\right) \geqslant 0 \quad \text { all feasible } \xi_{i}^{*} .
$$

Note that $W_{i}(\cdot)$ and $W_{i+1}(\cdot)$ differ only by a constant of proportionality. In light of (3)-(5), generations $i$ and $i+1$ both will want to maximize

$$
\sum_{j=i}^{\infty} \Delta^{i} \cdot\left[U^{2}\left(\xi_{j}^{2}\right)+U^{1}\left(\xi_{j+1}^{1}\right)\right]
$$

Expressions (3)-(5) embody the intense two-sided altruism outlined in the introduction: an old family cares about the consumption of its daughter's household exactly as if it were its own; the daughter cares about the consumption of her parents exactly as if it were her own. This is opposite to a simple life-cycle model without altruism: in such a model, as 
a child reaches maturity she and her parents cease to value one anothers consumption at all. The persistence of affection embodied in (3)-(6) seems like an interesting special case, and it leads to important simplifications of this paper's analysis: time consistency issues do not arise because of the geometric discounting; the implied commonality of interests between households within each family line allows us to assume that for the $T$ periods during which generations $i$ and $i+1$ overlap, they pool their resources and solve the joint maximization problem below. ${ }^{2,3}$

\section{Behavior}

First consider the deterministic case in which all families have the same innate earning ability. A household of age $s$ has $n(s)$ equivalent-adult members and supplies $l(s)$ natural units of labor. Let $N(s)=n(s)+n(s+T)$ and $L(s)=l(s)+l(s+T), s=1, \ldots, T$. Consider a $T$-period phase of a dynasty's decision problem, a phase immediately after the death of one member household and the formation of another. Let the phase start at time $t+1$ in Fig. 1. As indicated, think of parents and their adult daughter's household as pooling their resources and jointly acting to maximize (6).

Suppose, for the moment, that the dynasty takes as given its initial wealth $A$ and the wealth $B$ it must leave at the end of $T$ periods. Then it will choose consumption per adult, $C(s)$, and asset holdings, $a(s)$, to solve

$$
\max \sum_{s=1}^{T}(1+\delta)^{-s} \cdot N(s) \cdot \frac{C(s)^{\beta}}{\beta}
$$

subject to:

$$
\begin{gathered}
a(s+1)=(1+r) \cdot a(s)+w \cdot(1+\gamma)^{t+s} \cdot L(s)-N(s) \cdot C(s), \quad \text { all } s, \\
a(s) \geqslant 0, C(s) \geqslant 0, \quad \text { all } s, \\
a(1)=A, \quad a(T+1)=B .
\end{gathered}
$$

The feasible set for (7) is nonempty if and only if $B \leqslant(1+r)^{T}$. $\left[A+w \cdot(1+\gamma)^{t} \cdot Y(r)\right]$, where $Y(r)=\sum_{s=1}^{T}(1+\gamma)^{s} \cdot(1+r)^{1-s} \cdot L(s)$. The objective is strictly concave and the feasible set is compact and convex,

${ }^{2}$ Laitner [23] provides a more detailed discussion of such preferences and joint maximization. Clearly the precise treatment of deceased ancestors in (3)-(5) is irrelevant to current behavior.

${ }^{3}$ Note that Hori and Kanaya [15] would classify (3) as a special case of paternalistic preferences. Similarly, (3) corresponds to Kimball's [17] direct utility function (2), and we do not employ his functional restriction (1). Laitner [21] and Lindbeck and Weibull [24], for example, examine complications arising from strategic behavior when different parties within the same line of descent favor themselves over others. 
so a solution exists and it is unique. Let $F\left(A, B ; w \cdot(1+\gamma)^{t}, r\right)$ denote the maximized value of the objective function. Standard properties of $F(\cdot)$ can be established--continuity, monotonicity, and concavity. It can also be shown that the optimal policy functions describing the maximizing values for consumption and asset holding for all ages $s=1, \ldots, T$ are single-valued and continuous. In addition, $F(\cdot)$ is homogeneous of degree $\beta$ jointly in its first three arguments, and the optimal policy functions are homogeneous of degree one.

The dynasty's intergenerational decision problem is then

$$
\max _{B_{j}} \sum_{j=i}^{\infty} A^{j} \cdot F\left(B_{j}, B_{j+1} ; w \cdot(1+\gamma)^{t+(j-i) \cdot T}, r\right),
$$

subject to:

$$
0 \leqslant B_{j+1} \leqslant(1+r)^{T} \cdot\left[B_{j}+w \cdot(1+\gamma)^{t+(j-i) \cdot T} \cdot Y(r)\right], \quad \text { all } j \geqslant i,
$$

given $B_{i} \geqslant 0$. Behavior according to (8) will maximize (6) for generations $i$ and $i+1$. Without loss of generality, set $w=1$. Since $F(\cdot)$ is homogeneous of degree $\beta$ and the wage is growing at the rate $\gamma$, it is convenient to define

$$
v\left(A, A^{\prime} ; r\right) \equiv F\left(A,(1+\gamma)^{T} \cdot A^{\prime} ; 1, r\right) .
$$

Let $\rho(r) \equiv[(1+r) /(1+\gamma)]^{T}$. Note that $v(\cdot)$ is well defined if and only if $A^{\prime} \leqslant \rho(r) \cdot[A+Y(r)]$.

Without loss of generality, set $t=0$ and $i=0$ in Fig. 1. Letting

$$
A_{j} \equiv B_{j} /(1+\gamma)^{j \cdot T}, \quad \Gamma \equiv(1+\gamma)^{\beta \cdot T},
$$

and again making use of homotheticity, we can write the dynasty's intergenerational maximization problem as

$$
\max \sum_{j=0}^{\infty} \Gamma^{j} \cdot \Delta^{j} \cdot v\left(A_{j}, A_{j+1} ; r\right)
$$

subject to:

$$
0 \leqslant A_{j+1} \leqslant \rho(r) \cdot\left[A_{j}+Y(r)\right], \quad \text { all } j \geqslant i,
$$

given $A_{0} \geqslant 0$. The corresponding dynamic program is

$$
V(A ; r)=\max \left\{v\left(A, A^{\prime} ; r\right)+\Gamma \cdot \Delta \cdot V\left(A^{\prime} ; r\right)\right\}
$$

subject to:

$$
0 \leqslant A^{\prime} \leqslant \rho(r) \cdot[A+Y(r)], \text { all } A \geqslant 0 .
$$


Given the parameter constraint

$$
\Gamma \cdot \Delta<1
$$

Laitner [23] analyzes (9)-(10).

The present paper turns to the stochastic case. Let $l^{*}(s, Z)$ denote the labor supply at age $s$ of a household with ability $Z$. A family's $Z$ is now a sampling from random variable $\tilde{Z}$. The latter has (exogenously given) density $p(Z), p(\cdot)$ is continuous and positive for $Z \in \mathscr{Z} \equiv[0,1]$, and 0 elsewhere. A family's sampling $Z$ becomes evident at its inception. Assume $l^{*}(\cdot)$ is nonnegative and continuous in $Z$. It will be convenient to distinguish between $l^{*}(s, Z)$ and the same household's "schedule of hours receiving compensation" $l(s, Z)$. The latter corresponds to $l^{*}(s, Z)$ for ages prior to retirement, but it includes claims to social security benefits subsequently. This paper assumes ${ }^{4}$

$$
\infty>\zeta_{2} \geqslant \frac{\partial l(s, Z)}{\partial Z} \geqslant \zeta_{1}>0, \quad l(s, Z)>0 \quad \text { all } \quad s \in\{1, \ldots, 2 \cdot T\}, Z \in \mathscr{Z} .
$$

Earnings abilities are not heritable.

Letting $L\left(s, Z, Z^{\prime}\right) \equiv l\left(s, Z^{\prime}\right)+l(s+T, Z)$, problem (7) is unchanged except that $L(\cdot), Y(\cdot)$, and $F(\cdot)$ have the ability parameters $Z$ and $Z^{\prime}$ as additional arguments. As before, $F(\cdot)$ is homogeneous of degree $\beta$ jointly in $(A, B ; w)$, and optimal policy functions are homogeneous of degree one.

The dynasty's intergenerational problem is analogous to (8), with expected utility as the objective. As before, it is useful to renormalize and to set $w=1$, so we can write the dynasty's problem as

subject to:

$$
\max E\left[\sum_{j=0}^{\infty} \Gamma^{j} \cdot \Delta^{j} \cdot v\left(A_{j}, A_{j+1}, Z_{j}, Z_{j+1} ; r\right)\right]
$$

$$
0 \leqslant A_{j+1} \leqslant \rho(r) \cdot\left[A_{j}+Y\left(Z_{j}, Z_{j+1} ; r\right)\right], \quad \text { all } j \geqslant 0,
$$

given $\left(Z_{0}, Z_{1}, A_{0}\right)$, where the expectation is over the realization of the $Z_{j}$, $j>1$. The corresponding dynamic program is

$$
\begin{aligned}
V\left(A, Z, Z^{\prime} ; r\right)= & \max _{A^{\prime}}\left\{v\left(A, A^{\prime}, Z, Z^{\prime} ; r\right)+\Gamma \cdot A\right. \\
& \left.\cdot \int_{\mathscr{Z}} V\left(A^{\prime}, Z^{\prime}, Z^{\prime \prime} ; r\right) \cdot p\left(Z^{\prime \prime}\right) d Z^{\prime \prime}\right\},
\end{aligned}
$$

${ }^{4}$ These properties simplify the proofs in the appendix - see Lemma 5 , for example. They could follow in practice if, for example, there is a social security system in which benefits relate to a household's past earnings ability. 
subject to:

$$
0 \leqslant A^{\prime} \leqslant \rho(r) \cdot\left[A+Y\left(Z, Z^{\prime} ; r\right)\right], \quad \text { all } A \geqslant 0 .
$$

The next subsection first shows that (11) essentially ensures that (12) has a finite solution. Then, given (11), and a restriction on $r$-which turns out to hold in equilibrium - we show that it is legitimate to study (13) in place of (12). Third, we establish properties of $V(\cdot)$ and the corresponding policy functions. Fourth, we use the policy functions to associate, for each $r$, a joint distribution for $\left(A, Z, Z^{\prime}\right)$ with the density of $\bar{Z}$. Finally, we derive properties useful for establishing the existence and character of a steadystate equilibrium.

\section{Mathematical Results}

Define $r^{*}$ from

$$
\frac{1+r^{*}}{1+\delta}=(1+\gamma)^{1-\beta}
$$

Laitner [23] shows (with first-order conditions) that $r>r^{*}$ leads to wealth accumulation too rapid to sustain a steady-state equilibrium. In the present paper, the convexity of marginal utility and randomness of future earnings lead to still higher saving (for precautionary reasons) - see Proposition 3 and its interpretation below-so that $r>r^{*}$ continues to be uninteresting.

Turning to parameter restriction (11), suppose $\beta<0$. Then (11) follows under our assumptions $\gamma>0$ and $\delta \geqslant 0$. With (11), (12) is bounded above by zero and below by

$$
\sum_{j=0}^{\infty}[\Lambda \cdot \Gamma]^{j} \cdot v(0,0,0,0 ; r)>-\infty
$$

regardless of $r$. Suppose $\beta>0$. Then (12) is bounded below by zero. It is unbounded above if (11) fails; consider merely consuming earnings in every generation. Let (11) hold. The following is an upper bound for (12):

$$
\begin{aligned}
V^{U}(A ; r) & \equiv \sum_{j=0}^{\infty}[\Delta \cdot \Gamma]^{j} \cdot v\left(B_{j}(A ; r), 0,1,1 ; r\right), \\
B_{j}(A ; r) & \equiv[\rho(r)]^{j} \cdot A+\sum_{k=0}^{j}[\rho(r)]^{k} \cdot Y(1,1 ; r) .
\end{aligned}
$$

In turn, $V^{U}(\cdot)$ is finite if

$$
\begin{aligned}
1>\Delta \cdot \Gamma \cdot[\rho(r)]^{\beta} & =\left[\frac{(1+\gamma)^{\beta}}{1+\delta} \cdot\left(\frac{1+r}{1+\gamma}\right)^{\beta}\right]^{T} \\
& =\left[\frac{(1+r)^{\beta}}{1+\delta}\right]^{T} \Leftrightarrow 1>\frac{(1+r)^{\beta}}{1+\delta} .
\end{aligned}
$$


If $r \leqslant \gamma$,

$$
\left[\frac{(1+r)^{\beta}}{1+\delta}\right]^{T} \leqslant\left[\frac{(1+\gamma)^{\beta}}{1+\delta}\right]^{T}=\Delta \cdot \Gamma<1
$$

If $r^{*} \geqslant r>\gamma$

$$
\frac{1+r}{1+\delta} \leqslant(1+\gamma)^{1-\beta} \Rightarrow \frac{(1+r)^{\beta}}{1+\delta} \leqslant\left[\frac{1+\gamma}{1+r}\right]^{1-\beta}<1 .
$$

Thus, when $\beta>0,(11)$ is necessary for boundedness in (12), and it is sufficient provided $r \leqslant r^{*}$.

Proceeding with (11),

Proposition 1. Assume (11). Fix $w=1$ and $r \in\left[0, r^{*}\right)$. Then (i) problem (13) has a unique finite solution $V(\cdot)$, and $V(\cdot)$ also gives the maximized value of (12). (ii) The maximization in (13) uniquely defines a policy function,

$$
A^{\prime}=\Psi\left(A, Z, Z^{\prime} ; r\right),
$$

and $\Psi(\cdot)$ is single-valued, nondecreasing in $(A, Z)$, and continuous in $\left(A, Z, Z^{\prime} ; r\right)$. (iii) There exists a finite upper bound $A^{U}(r)$ such that $A>A^{U}(r)$ implies $A>\Psi\left(A, Z, Z^{\prime} ; r\right)$ all $Z, Z^{\prime} \in \mathscr{Z}^{5}{ }^{5}$

The policy function $\Psi(\cdot)$ determines a distribution of wealth among dynasties as follows. In Fig. 1, note that at the close of period $t$ two variables characterize the family line's state: $A_{i}$ and $Z_{i}$. The former registers the line's assets carried from $t$ to $t+1$ (recall that $A_{i} \cdot(1+\gamma)^{t}$ equals life-cycle saving for generation $i$ plus the bequest to generation $i$ from generation $i-1$ ); $Z_{i}$ gives the earning ability of the household continuing in life. Proposition 1 shows that steady-state equilibrium values of $A$ never wander above $A^{U}(r)$. Define the set

$$
\mathscr{S}(r) \equiv\left[0, A^{U}(r)\right] \times \mathscr{Z} .
$$

The policy function $\Psi(\cdot)$ and the density $p(\cdot)$ define a transition rule on $\mathscr{S}(r)$ : letting $\mu(\cdot)$ be the Lebesgue measure, for any Lebesgue measurable $\mathscr{X} \subseteq \mathscr{S}(r)$, and any $x \in \mathscr{S}(r)$,

$$
\Phi(x, \mathscr{X} ; r) \equiv \int_{\left\{Z^{\prime}:\left(\Psi\left(x, Z^{\prime} ; r\right), Z^{\prime}\right) \in \mathscr{X}\right\}} p\left(Z^{\prime}\right) \mu\left(d Z^{\prime}\right) .
$$

${ }^{5}$ Note that $\Psi(\cdot)$ may be decreasing in $Z^{\prime}$ : higher earnings for a child may lead his parents to leave a smaller estate. See, however, Lemma 5 in the Appendix. 
In other words, if the family line of Fig. 1 has state $\left(A_{i}, Z_{i}\right)$ at the close of period $t$, then the probability that it will close period $t+T$ with $\left(A_{i+1}, Z_{i+1}\right) \in \mathscr{X}$ is $\Phi\left(\left(A_{i}, Z_{i}\right), \mathscr{X} ; r\right)$.

Use the notation

$$
\begin{aligned}
\Phi^{0}(\cdot) & =\Phi(\cdot), \\
\Phi^{n+1}(x, \mathscr{X} ; r) & =\int \Phi^{n}\left(x^{\prime}, \mathscr{X} ; r\right) \cdot \Phi\left(x, d x^{\prime} ; r\right), \quad n=0,1, \ldots .
\end{aligned}
$$

Then

Proposition 2. Assume (11). Fix $w=1$ and $r \in\left[0, r^{*}\right)$. Then (i) $\Phi(x, \mathscr{X} ; r)$ is a uniquely defined probability transition rule for $x \geqslant(0,0)$ and Lebesgue measurable sets $\mathscr{X}$. (ii) $\Phi(\cdot)$ has a unique invariant measure $\phi(\cdot)$ on $\mathscr{S}(r)$; states outside of $\mathscr{S}(r)$ are infeasible or transitory. And, (iii) $\Phi^{n}(\cdot)$ is well defined for each $n \geqslant 0$ and $\lim _{n \rightarrow \infty} \Phi^{n}(x, \mathscr{X} ; r)=\phi(\mathscr{X} ; r)$ for all $x \in \mathscr{S}(r)$ (with the rate of convergence being uniform in $x$ and $\mathscr{X}$ ).

If $r \in\left[0, r^{*}\right)$, the private-sector's steady-state supply of wealth is now determined. To see this, consider an economy in a steady state. Dynasties are divided into $T$ groups of equal size, according to the timing of their life cycles. Within each of these $T$ groups there is a continuum of dynasties, differing in terms of wealth and earning abilities. Within each of these groups, the joint distribution of these variables is given by the invariant measure $\phi(\cdot)$ of Proposition 2 (note that given the independence of $Z_{i+1}$, $\phi(\cdot)$ and $p(\cdot)$ determine the distribution of tuples $\left.\left(A_{i}, Z_{i}, Z_{i+1}\right)\right)$. The distribution, (7), and the law of large numbers determine average wealth per dynasty: reintroducing a wage $w$, and called the maximizing $a(s)$ in our normalized version of (7), for a unit born at time $0, a\left(s, A, A^{\prime}, Z, Z^{\prime} ; r\right)$ for $s=1, \ldots, T$, average assets per family carried from date 0 to 1 equal

$$
\begin{aligned}
& w \cdot \int_{\mathscr{S}(r)} \int_{\mathscr{Y}} \sum_{s=1}^{T} \frac{(1+\gamma)^{-s} \cdot a\left(s, A, \Psi\left(A, Z, Z^{\prime} ; r\right), Z, Z^{\prime} ; r\right)}{T} \\
& \cdot p\left(Z^{\prime}\right) u\left(d Z^{\prime}\right) \phi(d A \times d Z ; r) .
\end{aligned}
$$

It will be convenient to have the supply relation in a simpler form. The average effective labor supply per family at time 1 is

$$
e_{1} \equiv \sum_{s=1}^{2 \cdot T} \frac{(1+\gamma)^{-s} \cdot E\left[l^{*}(s, \tilde{Z})\right]}{2 \cdot T} .
$$

In a steady state, technological progress causes this and (16) to grow proportionately over time. So,

$$
r(r) \equiv \frac{\text { expression }(16)}{e_{1} \cdot w}
$$


independent of both $t$ and $w$. It gives the steady-state supply of wealth normalized by the wage bill. We have

Proposition 3. Assume (11). Fix $w$ and $r \in\left[0, r^{*}\right)$. Let $Y(\cdot)$ be as in (17). Then (i) $r(\cdot)$ is continuous and finite all $r \in\left[0, r^{*}\right)$, and $\lim _{r \rightarrow r^{*}} Y(r)=\infty$. Using the notation of Fig. 1, let generation $i$ have state $\left(A_{i}, Z_{i}\right)$. Let $P\left(A_{i}, Z_{i}, \tau ; r\right)$ be the probability that for at least one date between $t$ and $t+\tau$, in the line either a lifetime or intergenerational asset non-negativity constraint binds. Then (ii) $\lim _{\tau \rightarrow \infty} P\left(A_{i}, Z_{i}, \tau ; r\right)=1$ any $\left(A_{i}, Z_{i}\right) \in \mathscr{S}(r)$.

\section{Steady-State Equilibrium}

Figure 2 identifies steady-state equilibria for this paper's model. For each $r \in\left[0, r^{*}\right)$, the preceding section derives the unique $K_{t} /\left[w \cdot E_{t}\right]=Y(r)$ which is both time invariant and consistent with utility maximization on the part of all households. Figure 2 graphs the ratio as its "supply curve" $S$.

An aggregate production function and competitive factor pricing lead to a second relationship between $r$ and overall factor intensities. For example, a Cobb-Douglas function, competitive pricing, and equal proportional tax rates on wages and interest imply

$$
\frac{K_{t}}{w_{t} \cdot E_{t}}=\frac{\alpha}{1-\alpha} \cdot \frac{1}{r_{t}} .
$$

In Fig. 2, $D$ is the locus of points satisfying such an equation. The intersection of $D$ and $S$ determines a steady-state equilibrium.

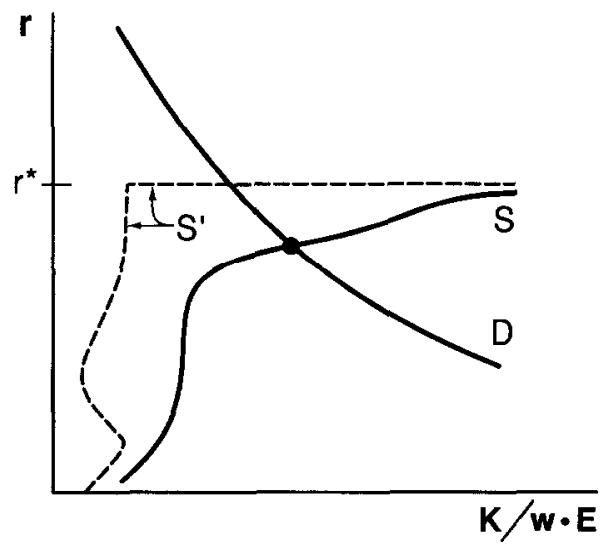

Fig. 2. The steady-state supply (S) and demand (D) for wealth. 
Proposition 3 shows that $\Upsilon(r)$ is finite each $r \in\left[0, r^{*}\right)$, continuous in $r$, and asymptotically infinite as $r \uparrow r^{*}$. Thus, given (18), at least one intersection exists.

\section{Interpretations}

Laitner [23] describes a model similar to the one here but lacking heterogeneous earnings abilities. The $S$ curve then resembles $S^{\prime}$ in Fig. 2: For $r>r^{*}$ saving is so attractive that steady-state wealth is unlimited. For $r=r^{*}$, family lines want to equalize their consumption per equivalent adult, normalized for technological progress, across generations; hence, dynastic wealth is husbanded - only interest income on inherited wealth in excess of rate $\gamma$ is consumed during the lifetime of any generation. Any aggregate amount of wealth sufficient to ensure that lifetime liquidity constraints never bind (within any family line) is therefore sustainable, giving the flat part of $S^{\prime}$. Ricardian neutrality prevails for equilibria at $r=r^{*}$; the distribution of wealth across family lines depends on initial conditions; and, a change in earnings or family composition profiles would shift $S^{\prime}$ horizontally-leaving the intersection of $D$ and $S^{\prime}$ unchanged.

For a steady state with $r<r^{*}$ in Laitner [23], nonnegativity constraints on lifetime assets and/or bequests bind methodically every $T$ years in every family linc. Ricardian neutrality is absent. As a practical matter, simulations with interest rates in this range generate supply curves, and corresponding equilibria, far to the left, leaving most of the observable stock of wealth unexplained.

As stated, the present paper's random samplings from $\tilde{Z}$ and isoelastic utility functions imply additional saving for precautionary reasons. Hence even $r=r^{*}$ cannot be a steady-state equilibrium. That is one key implication of our analysis.

The reason $r<r^{*}$ is so important is as follows. When $r<r^{*}$, first-order conditions show that one generation in a dynasty will not desire consumption for its descendants equal or higher than its own. A generation enjoying a very high $Z$ may want to share its good luck through a bequest, but the first-order conditions show that its generosity will be limited. That leads to part (iii) of Proposition 1.

Almost the same logic generates the uniqueness of the stationary distribution in Proposition 2: a household with very bad luck must realize that its descendants cannot do worse, and, given $r<r^{*}$, it has no wish to sacrifice in order to make their consumption as high or higher than its own. Since long strings of very low samplings from $\tilde{Z}$ are inevitable for any family line over enough time, every dynasty eventually experiences a minimal $A$. Therefore the minimal state is in every ergodic set for $\Phi(\cdot)$, implying there is only one.

The inevitable appearance of the minimal state plus the assumed proper- 
ties of the density for $\tilde{Z}$ also establish the so-called hypothesis of Doeblin (see Stokey and Lucas [32, pp. 345-348]), which leads to the (strong) convergence of Proposition 2, part (iii). Similarly, part (ii) of Proposition 3 follows: a string of very low $Z$ 's within a dynasty takes it close to a minimal pair $(A, Z)$; since descendants are almost sure to be better off, the current generation will, near the minimal pair, want to borrow against the dynasty's future earnings - implying binding liquidity constraints. None of the model's steady states will then exhibit Ricardian neutrality. (Laitner [20] and Feldstein [12] report related findings).

A second key implication of the analysis also follows from the fact that precautionary saving makes $r\left(r^{*}\right)$ unbounded: $r(r) \rightarrow \infty$ as $r \uparrow r^{*}$ is then a continuity result. Without random earnings, it would not be-since $Y\left(r^{*}\right)$ could take finite values.

The divergence of $\gamma(r)$ at $r^{*}$ means that this paper's model can generate steady-state wealth levels matching empirical observation without resorting to exceptional interest rates-so that an important liability of conventional overlapping generations formulations seems to have been eliminated. The divergence also implies that we can reach high wealth ratios in Fig. 2 without $Y(r)$ becoming perfectly interest elastic as it does in the simplest representative agent formulations.

For the nonstochastic model of Laitner [23], in a steady state, either liquidity constraints never bind (and $r=r^{*}$ ) or they bind every $T$ years in every dynasty (and $r<r^{*}$ ). In the present paper, the two halves of Proposition 3 taken together imply that life-cycle and dynastic considerations must both come into play for equilibria near $r^{*}$ : on the one hand, because lifecycle wealth will be uniformly bounded for all $r \leqslant r^{*}$, dynastic wealth accumulation must assume a role - in fact, eventually a preponderant role--as $Y(\cdot)$ diverges; on the other hand, the last part of Proposition 3 requires binding liquidity constraints within part of each cross section-so that some family units must have a time horizon of $T$ years or less. In practice, some dynasties will have high recent samplings from $\tilde{Z}$, and their current households will leave estates. Others will currently enjoy moderately good luck and will bequeath modest amounts to ensure their descendants against very low future $Z$ 's. Households in dynasties enduring bad luck will be liquidity constrained. Proposition 5 below views this last group again, in a slightly different way.

\section{Lifetime LiQuidity Constraints}

One would speculate that the existence of lifetime liquidity constraints tends to enhance intergenerational-transfer activity. This section verifies that conjecture. It then turns to the question of who will be constrained. 
Proposition 5 suggests that binding constraints will tend to fall most frequently on low-resource families.

For the moment, drop the lifetime liquidity constraint $a(s) \geqslant 0$ of (7). Then Proposition 1 generates a policy function for the new formulation, say, $\Psi^{*}\left(A, Z, Z^{\prime} ; r\right)$. The proof of Proposition 3 shows

$$
\Psi\left(A, Z, Z^{\prime} ; r\right) \geqslant \Psi^{*}\left(A, Z, Z^{\prime} ; r\right) \quad \text { all } r<r^{*} .
$$

The intuition is as follows: Binding lifetime liquidity constraints tend to make consumption early in life lower and later in life higher for given total resources; a low marginal utility of consumption late in life and a high marginal utility early both encourage large bequests.

Line (19) shows that the upper bound $A^{U}(r)$ in Proposition 1 remains in force in the absence of lifetime constraints. The formulation without lifetime constraints generates a stochastic transition function, say, $\Phi^{*}(x, \cdot ; r): \mathscr{I}(r) \rightarrow[0,1]$, corresponding to $\Phi(\cdot)$. Simplified versions of Propositions 2-3 yield a unique invariant measure $\phi^{*}(\cdot)$,

$$
\begin{aligned}
\int_{\mathscr{S}\{r\}} & \Phi^{*}\left(x^{\prime}, \mathscr{X} ; r\right) \phi^{*}\left(x, d x^{\prime} ; r\right) \\
& =\phi^{*}(\mathscr{X} ; r) \quad \text { all Lebesgue measurable } \mathscr{X} \subseteq \mathscr{S}(r),
\end{aligned}
$$

and a function $Y^{*}(r)$ giving the normalized supply of capital for interest rates $r<r^{*}$.

Proposition 4 shows that lifetime liquidity constraints tend to raise overall private-sector wealth accumulation.

Proposition 4. Assume (11). Fix any $r \in\left[0, r^{*}\right)$ and set $w=1$. Let $\phi(\cdot)$ be as in Proposition 2, and let $\Upsilon(\cdot)$ be as in (17). Let $\phi^{*}(\cdot)$ and $Y^{*}(\cdot)$ be as above - applying in the formulation without lifetime liquidity constraints. Let $(\bar{A}(r), \bar{Z})=\int(A, Z) \phi(d A \times d Z ; r)$ and $\left(\bar{A}^{*}(r), \bar{Z}^{*}\right)=\int(A, Z) \phi^{*}(d A \times d Z ; r)$. Then (i) $\bar{A}(r) \geqslant \bar{A}^{*}(r)$ (of course, $\bar{Z}=\bar{Z}^{*}$ ) and (ii) $r(r) \geqslant \gamma^{*}(r)$.

Part (i) follows from (19) and the last section of Proposition 2. Proceeding to (ii), lifetime liquidity constraints make $r(r)$ higher than $Y^{*}(r)$ because higher asset holdings for heirs will tend to follow from the higher inheritances of part (i); a "unit" (see (7)) desiring to make a larger intergenerational transfer will lower its lifetime consumption-hence its assets holdings will tend to be higher; and, by ruling out negative net worth, liquidity constraints will tend to raise life-cycle asset holdings. Section 4 provides some quantitative results.

Proposition 3 shows that once we incorporate heterogeneity of earnings, periods with binding lifetime and/or intergenerational asset constraints are 
inevitable over time, in any steady state, for every dynasty. The next proposition attempts to indicate where in a cross section of households binding constraints are the most likely to appear.

Proposition 5. Let (11) hold, $w=1$, and $r \in\left[0, r^{*}\right)$. Suppose $/(s, Z)=$ $Z \cdot l(s, 1)$ for all $Z$ and $s$. Let $\lambda>1$. Then (i) $\Psi\left(\lambda \cdot A, \lambda \cdot Z, \lambda \cdot Z^{\prime} ; r\right) \geqslant$ $\lambda \cdot \Psi\left(A, Z, Z^{\prime} ; r\right)$. (ii) Comparing family units with tuples $\left(A, Z, Z^{\prime}\right)$ and $\left(\lambda \cdot A, \lambda \cdot Z, \lambda \cdot Z^{\prime}\right), \lambda>1$, the latter will be subject to binding constraints for the same or fewer periods (out of $T$ ) than the former.

To interpret Proposition 5 consider first a life-cycle model with no transfers between families, with identical and homothetic preference orderings and with earnings' profiles which are simple multiples of one another across families. Then family consumption and asset profiles will be multiples of one another: if one family is constrained, all will be and at exactly the same ages. Neither the poor nor the rich will be especially prone to binding lifetime constraints. Turning to the model of this paper, underlying preferences are homothetic. However, even with the linearity of $l(\cdot)$ in Proposition 5, dynastic earnings profiles are not simple multiples of one another-any two dynasties will have the same joint density for future $Z$ 's but their current realizations will randomly differ. Different earnings patterns will lead to different sequences of binding constraints.

We can say more. Intergenerational transfers will be luxury goods: as we augment a unit's lifetime consumption, its corresponding marginal utility drops; if we augment its intergenerational transfer, the recipient will tend (eventually at least) to share with its descendants, so the decline in marginal utility for the recipient will be slower. Hence, a dynasty's optimizing intergenerational transfer will tend to rise more than proportionately with its current resources. ${ }^{6}$

Given the luxury good nature of intergenerational transfers, Proposition 5 emerges: comparing dynasties having current families of the same age and current tuples $\left(A, Z, Z^{\prime}\right)$ and $\left(\lambda \cdot A, \lambda \cdot Z, \lambda \cdot Z^{\prime}\right), \lambda>1$, in the latter current lifetime consumption will tend to be less than $\lambda$ times as high because of a more than proportionately larger bequest-thus lifetime liquidity constraints will be less of a current issue for the second dynasty.

Recently empirical work seems to find evidence of binding liquidity constraints for $20 \%$ or more of U. S. households-see, for example, Hall and Mishkin [14], Zeldes [39], and Campbell and Mankiw [8]. While a simple life-cycle model might imply the incidence of binding constraints would depend exclusively on age, Proposition 5 implies that current and past earnings differences will be an additional explanatory factor.

\footnotetext{
${ }^{6}$ See Laitner [20] and the empirical results in Menchik and David [28].
} 
A final result is even more straightforward: all other factors being equal, a unit in (7) receiving a larger intergenerational transfer will be less likely to be burdened by lifetime liquidity constraints. Compare two dynasties with the timing of Fig. 1. At $t+1$, let one have tuple $\left(A^{\prime}, Z, Z^{\prime}\right)$ and the other $\left(A, Z, Z^{\prime}\right), A^{\prime}>A$. Current consumption will be less than proportionately higher for the former-note that $Z$ and $Z^{\prime}$ apply to both. Furthermore, the former receives a higher proportion of its resources for $t+1, \ldots, t+T$ at $t+1$. Thus, an examination of (7) shows the former dynasty will suffer fewer periods of binding liquidity constraints in the near future.

\section{Simulations and the Timing of Inter Vivos Transfers}

This section presents several numerical examples. Parameter values are chosen from the existing literature. All simulations employ $\gamma=0.0187-$ Denison [10, Table 8-4] identifies a growth rate of per capita potential national income of $2.25 \%$ for the halcyon period 1948-1973, and the portion due to labor quality and output per unit of input is $1.87 \%$.

The simulations use Tobin's [34] "equivalent adults" scale: minor children consume $60 \%$ as much as aduits, and teenagers $80 \%$. They set $T=26$ : A household begins with a 20 -year-old male and a 20 -year-old female; in its sixth year it has two children; as the parents turn 46, the children have left home to form their own families; and, the parents live on through age 71. Unlike Tobin, for simplicity this paper assumes a certain age of death. (Experiments with uncertain life spans (and annuities) showed small differences in Table I for this paper's model-though somewhat larger differences in Table II. Trials with Mariger's [26] estimated adult equivalences seemed to cause few additional changes.)

As in Section 1, in the simulations $l(s, Z)$ has two components. The first is labor income and has the form

$$
Z \cdot \bar{l}(s) \cdot(1-\tau)
$$

with $s$ age, $Z$ an (ability) sampling from $\tilde{Z}$, and $\tau$ a proportional tax rate--set to 0.15, as in Auerbach and Kotlikoff [2]. The profile $\bar{l}(\cdot)$ comes from the median earnings by age figures for 1972 of the Social Security Bulletin, Annual Statistical Supplement [36]. Male and female earnings were separately multiplied by participation rates from Employment and Earnings [37], then by survival probabilities, and then summed. This section assumes $\tilde{Z}$ is truncated log-normal. The variance is Dooley and Gottschalk's [11, Table 1] estimate (from Census data for 1972) of the within-cohort variance of the logarithm of earnings for males, 0.451 . The 
support ends at three standard deviations on each side of the mean; maximal earnings are about 56 times the minimum.

The second component, capturing social security benefits, is

$$
Z^{*} \cdot \breve{l}(s)
$$

where $\breve{l}(s)$ includes average male social security retirement benefits for 1972 (see [36]) multiplied by survival probabilities, and the same for females (including retired women, wives of retired workers, and widows), and $Z^{*}$ is a draw from $\tilde{Z}^{*}$. The distribution of $\tilde{Z}^{*}$ is the actual 1972 distribution of retirement awards-see [36, Table 55]-with the mean normalized to one. We assume that $\tilde{Z}$ and $\tilde{Z}^{*}$ are perfectly correlated-- higher earnings implying higher stationary-state benefits. So, for a nondecreasing function $\Omega(\cdot), \tilde{Z}^{*}=\Omega(\tilde{Z})$. Then

$$
l(s, Z) \equiv Z \cdot \tilde{l}(s) \cdot(1-\tau)+\Omega(Z) \cdot \check{l}(s) .
$$

Figure 3 graphs this section's "effective adults" and labor earnings profiles $n(s)$ and $l(s, 1), s=1, \ldots, 72$.

Recent work by Zeldes [39] points to a value for $\beta$ near -1 . The tables try $\beta=-1$ with $\delta=0$ and 0.02 . As Auerbach and Kotlikoffs [2, pp. 50-51] literature survey suggests $\beta=-3$, this paper's third trial uses $\beta=-3$ and $\delta=0$. Results are qualitatively similar for all three cases. Note that for $\beta=-1$ and $\delta=0, r^{*}=0.0377$; for $\beta=-1$ and $\delta=0.02$, $r^{*}=0.0585$; and, for $\beta=-3$ and $\delta=0, r^{*}=0.0769$.

Each simulation determines $Y(r)$ for various values $r \in\left[0, r^{*}\right)$. The calculations employ a grid over $\mathscr{Z}$ with 20 intervals, and over $A$ values of about 250 . The total number of grid rectangles for the space of tuples

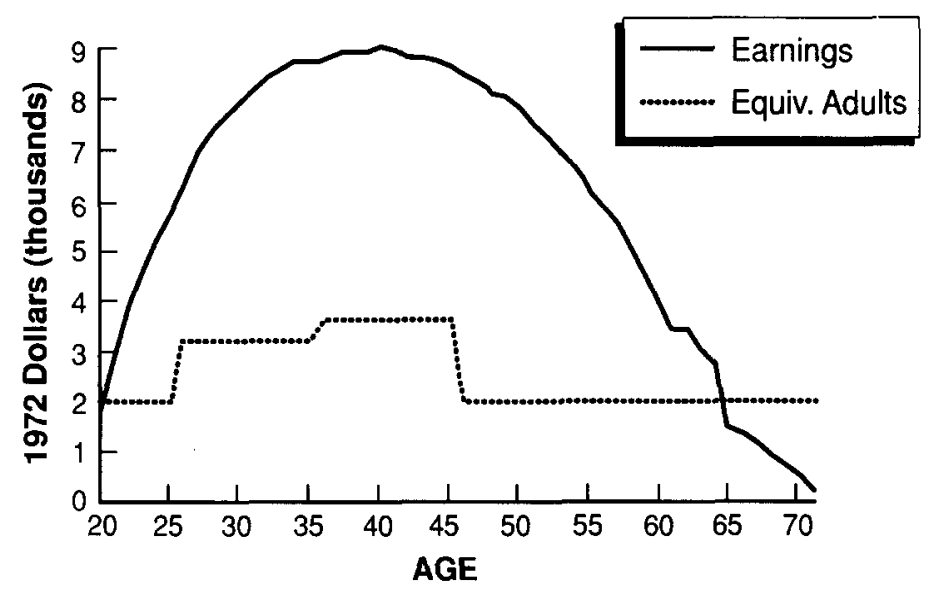

FIG. 3. Family earnings and equivalent adult profiles. 
$\left(A, Z, Z^{\prime}\right)$ is then $250 \times 20 \times 20$. The steps are: use successive approximations as in Bellman [4] or Stokey and Lucas [32, p. 266]; generate a sequence of indirect utility functions and corresponding intergenerational transfer rules $\Psi^{k}(\cdot)$ - the latter converging to $\Psi(\cdot)$. (Note that the computer need only store a sequence of bivariate functions $E_{Z^{\prime}}\left[\partial V^{k}\left(A, Z, \tilde{Z}^{\prime}\right) / \partial A\right]$ in this stage.) Proposition 2 takes $\Psi(\cdot)$ to the transition rule $\Phi(\cdot)$. Iteratively form Proposition 2's invariant measure $\phi(\cdot)$, as in the proposition's third part. Combining probabilities from $\phi(\cdot)$ over a grid on $\mathscr{S}(r)$ with independent samplings for $Z^{\prime}$ from $\tilde{Z}$, we have a distribution of tuples $\left(A, Z, Z^{\prime}\right)$. Our life-cycle framework from (7) and $\Psi(\cdot)$ associate a lifetime asset profile with each tuple. Using probability weights from $\phi(\cdot)$ and $p(\cdot)$ and averaging over ages, one can deduce average family-unit wealth holdings. Dividing by average labor supplied times $w$ yields $K /(w \cdot E)$. The 1972 empirical ratio of the wage bill to GNP was 0.6645 (assuming that proprietor's income followed the same fractional breakdown between earnings and return to capital as was true for the remainder of national income), and Table I presents results in the form $K / G N P=0.6645 \cdot K /(w \cdot E)$.

The second column of Table I presents stationary-equilibrium wealth-toGNP ratios for a life-cycle model (in which life spans are $2 \cdot T$ ) with no transfers between families or generations and no lifetime liquidity constraints. The third column modifies the same model to include lifetime constraints. The fourth expands to our framework with intergenerational transfers, but omits lifetime liquidity constraints for family units. The fifth column refers to the model of this paper.

Adding Musgrave's [29] 1972 figure for U. S. net reproducible private capital ( 4655.0 billion 1982-\$), the corresponding measure of the stock of consumer durables (740.0 billion 1982-\$), the 1972 national accounts measure of inventories (612.4 billion 1982-\$), Seater's [30] 1972 market value of government debt (235.0 billion 1982-\$), and the average of the 1970 and 1974 values of land from [35] (1981.2 billion 1982-\$) yields an empirical ratio of private wealth to GNP of 3.15. Proposition 3 indicates that our model will have no difficulty generating wealth numbers as large as this. In fact, column 5 of Table I shows that one can obtain ratios in the range of three with parameter values and interest rates having magnitudes that are familiar from other studies.

The graph following Table I displays the asymptotic behavior of Proposition 3. It also shows that the $S$-curve for this example is far from perfectly interest elastic in the empirically important range.

Thurow [33, Fig. 1] plots Bureau of Labor Statistics consumption data for the early 1960's. His graph shows consumption varying little with age in the cross section. That is consistent with a steady state in which average consumption per equivalent adult rises, with household age, at the rate of 
technological change. Recall that $\gamma=0.0187$ here. With $r=0.0225, \beta=-1$, and $\delta=0$ or $r=0.045, \beta=-1$, and $\delta=0.02$, simulated aggregate average consumption per adult rises $1.3 \%$ per year of age; with $r=0.030, \beta=-3$, and $\delta=0$, the average rate of consumption increase is $1.9 \%$. Hence, the model seems in rough agreement with Thurow's consumption figures.

Returning to Table I, columns 2-3 show that the simple life-cycle model does poorly in explaining the economy's capital intensity. That is consistent with Kotlikoff and Summers [18]. It also follows the pattern of a great deal of simulation work-see this paper's introduction.

Comparing columns 4 and 5 for wealth ratios near three, we find that lifetime liquidity constraints account for one-eighth to one-quarter of the steady-state wealth supply. (Trials with adult mortality tended to show lifetime constraints accounting for about one-third of all wealth.)

TABLE I

Steady-State Equilibrium Wealth-to-GNP Ratios

\begin{tabular}{|c|c|c|c|c|}
\hline \multirow[b]{2}{*}{$\begin{array}{l}\text { Interest } \\
\text { rate }\end{array}$} & \multicolumn{4}{|c|}{ Model } \\
\hline & Life cycle & $\begin{array}{l}\text { Life cycle } \\
\text { with } \\
\text { liquidity } \\
\text { constraints }\end{array}$ & $\begin{array}{c}\text { Inter- } \\
\text { generational } \\
\text { life cycle }\end{array}$ & $\begin{array}{c}\text { Inter- } \\
\text { generational } \\
\text { life cycle } \\
\text { with liquidity } \\
\text { constraints }\end{array}$ \\
\hline \multicolumn{5}{|c|}{ Parameters $^{a}: \beta=-1, \delta=0$} \\
\hline 0.000 & -0.767 & 0.788 & 0.515 & 0.823 \\
\hline 0.015 & -0.194 & 0.861 & 1.487 & 1.946 \\
\hline 0.0225 & 0.083 & 0.901 & 2.855 & 3.476 \\
\hline 0.030 & 0.357 & 0.953 & 7.451 & 7.943 \\
\hline \multicolumn{5}{|c|}{ Parameters $^{\alpha}: \beta=1, \delta=0.02$} \\
\hline 0.000 & -1.849 & 0.673 & 0.067 & 0.363 \\
\hline 0.015 & -1.231 & 0.740 & 0.340 & 0.606 \\
\hline 0.030 & -0.664 & 0.810 & 0.899 & 1.237 \\
\hline 0.045 & -0.128 & 0.889 & 3.024 & 3.558 \\
\hline 0.0525 & 0.134 & 0.939 & 8.990 & 0.579 \\
\hline \multicolumn{5}{|c|}{ Parameters $^{a}: \beta=-3, \delta=0$} \\
\hline 0.000 & -0.767 & 0.788 & 0.663 & 1.114 \\
\hline 0.015 & -0.591 & 0.815 & 1.156 & 1.602 \\
\hline 0.030 & -0.414 & 0.843 & 1.917 & 2.474 \\
\hline 0.045 & -0.236 & 0.871 & 3.587 & 4.088 \\
\hline 0.060 & -0.058 & 0.909 & 8.016 & 8.437 \\
\hline 0.070 & 0.059 & 0.934 & 18.300 & 21.348 \\
\hline
\end{tabular}

${ }^{a}$ All other parameters as in text. 
Table II presents additional details for this paper's model. For a steadystate equilibrium, columns $2-4$ give the fractions of family units subject, at some time in their lives, to binding lifetime liquidity constraints, binding intergenerational transfer constraints on their estates, or at least one of the two. For trials with very large wealth ratios, the fractions are small. For wealth ratios around three, however, the lifetime constraint numbers are about $20 \%$. That would imply that less than $20 \%$ of the families within a cross section would be experiencing a binding constraint currentlywhereas the empirical work cited in Section 3 seems to imply that at least $20 \%$ are.

The hypotheses of Propositions 5 are not satisfied due to our distribution of social security payments. Nevertheless, its general implication remains valid. For each $Z$ and $Z^{\prime}$ there is a critical $A$, above which a family unit with tuple $\left(A, Z, Z^{\prime}\right)$ is not subject to lifetime liquidity constraints and below which it is. Consider the case with $r=0.045, \beta=-1$, and $\delta=0.02$, for example. The top realizations of $Z$ and $Z^{\prime}$ are 56 times as large as the lowest ones, yet, in the simulations, for the highest $Z$ 's the critical $A$ is actually more than $50 \%$ smaller than for the minimal ones-it certainly does not rise in proportion to lifetime earnings.

Column 5 of Table II considers the breakdown of life-cycle saving and bequests. Note that if an average family receives a bequest of $b$, the average amount bequeathed $T$ years later is $b \cdot(1+\gamma)^{T}$. We might then think of the cohort's average "dynastic wealth" $s$ years from now as $b \cdot(1+\gamma)^{s}$. Similarly, if the average bequest realized now is $b$, a unit currently age $s$ will on average have received $b \cdot(1+\gamma)^{-s}$, and its current dynastic wealth will be $b \cdot(1+\gamma)^{-s} \cdot(1+\gamma)^{s}=b$. In this light, if we have $m$ "units" of each age $s=1, \ldots, T$, we might think of "dynastic wealth" in the economy as $m \cdot T \cdot b$. With $r=0.0225, \beta=-1$, and $\delta=0$, simulated dynastic wealth is

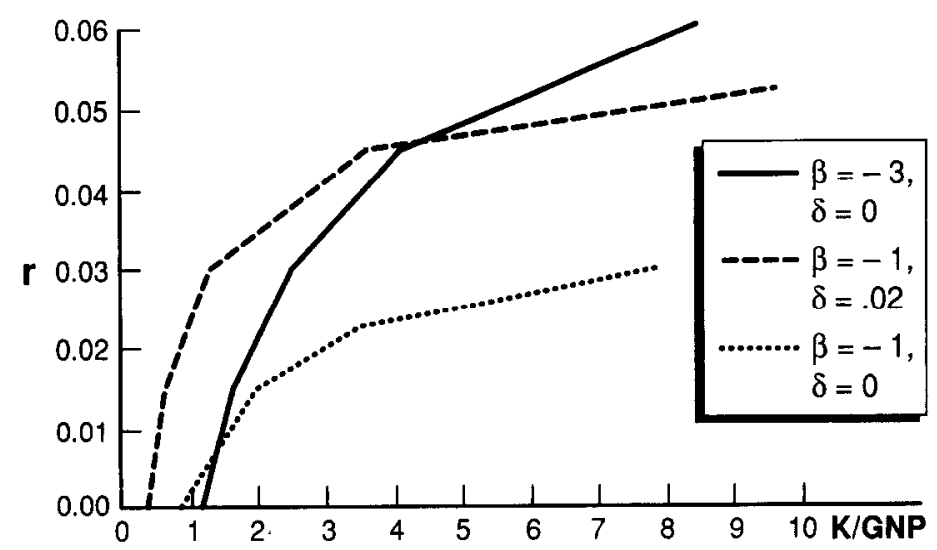

Fig. 4. The steady-state supply of wealth from the simulations. 
about $58 \%$ of all private wealth; with $r=0.045, \beta=-1$, and $\delta=0.02$, the share is about $67 \%$; with $r=0.03, \beta=-3$, and $\delta=0$, it is about $57 \%$. Kotlikoff and Summers [18] favored a somewhat larger numbers-more in the range of $80 \%$.

The last two columns of Table II give average amounts transferred inter vivos within family units as fractions of GNP. Table II determines inter vivos transfers as follows. A family "unit"--see (7) - consists of a parent family of age $T+1$ to $2 \cdot T$ and a descendant family of age 1 to $T$. If the unit has tuple $\left(A, Z, Z^{\prime}\right)$, it will want to end with assets $A^{\prime}=\Psi\left(A, Z, Z^{\prime}\right)$. The tuple and $A^{\prime}$ enable one to construct the unit's time path of consumption. Our equivalent adults' scale yields separate consumption profiles for

TABLE II

Characteristics of Steady-State Equilibria for Intergenerational Life-Cycle Model with Lifetime Liquidity Constraints

\begin{tabular}{|c|c|c|c|c|c|c|}
\hline \multirow[b]{2}{*}{$\begin{array}{l}\text { Interest } \\
\text { rate }\end{array}$} & \multicolumn{3}{|c|}{$\begin{array}{l}\text { Fraction of family units } \\
\text { subject to binding constraints }\end{array}$} & \multicolumn{3}{|c|}{$\begin{array}{l}\text { Cross-sectional ratio of } \\
\mathrm{X} \text {-to-GNP for } \mathrm{X}= \\
\text { current flow of }\end{array}$} \\
\hline & Lifetime & $\begin{array}{l}\text { Inter- } \\
\text { genera- } \\
\text { tional }\end{array}$ & Either & Bequests & $\begin{array}{c}\text { Inter } \\
\text { vivos } \\
\text { transfers } \\
\text { to young } \\
\text { families }\end{array}$ & $\begin{array}{c}\text { Inter } \\
\text { vivos } \\
\text { transfers } \\
\text { to old } \\
\text { families }\end{array}$ \\
\hline \multicolumn{7}{|c|}{ Parameters $^{a}: \beta=-1, \delta=0$} \\
\hline 0.000 & 0.551 & 0.704 & 0.772 & 0.009 & 0.044 & 0.055 \\
\hline 0.015 & 0.349 & 0.439 & 0.549 & 0.034 & 0.051 & 0.043 \\
\hline 0.0225 & 0.235 & 0.272 & 0.373 & 0.078 & 0.063 & 0.032 \\
\hline 0.030 & 0.086 & 0.101 & 0.151 & 0.233 & 0.102 & 0.017 \\
\hline \multicolumn{7}{|c|}{ Parameters $^{a}: \beta=-1, \delta=0.02$} \\
\hline 0.000 & 0.710 & 0.882 & 0.895 & 0.002 & 0.049 & 0.062 \\
\hline 0.015 & 0.609 & 0.785 & 0.819 & 0.006 & 0.050 & 0.058 \\
\hline 0.030 & 0.465 & 0.563 & 0.650 & 0.021 & 0.056 & 0.050 \\
\hline 0.045 & 0.199 & 0.226 & 0.315 & 0.092 & 0.094 & 0.032 \\
\hline 0.0525 & 0.052 & 0.059 & 0.088 & 0.312 & 0.216 & 0.014 \\
\hline \multicolumn{7}{|c|}{ Parameters $^{a}: \beta=-3, \delta=0$} \\
\hline 0.000 & 0.492 & 0.566 & 0.696 & 0.016 & 0.044 & 0.051 \\
\hline 0.015 & 0.409 & 0.441 & 0.571 & 0.028 & 0.046 & 0.050 \\
\hline 0.030 & 0.260 & 0.290 & 0.396 & 0.054 & 0.065 & 0.038 \\
\hline 0.045 & 0.137 & 0.135 & 0.210 & 0.110 & 0.101 & 0.028 \\
\hline 0.060 & 0.031 & 0.027 & 0.047 & 0.272 & 0.226 & 0.012 \\
\hline 0.070 & 0.002 & 0.001 & 0.003 & 0.759 & 0.660 & 0.002 \\
\hline
\end{tabular}

${ }^{a}$ Other parameter values as in text. 
each of the two families in the unit. We assign the entire initial asset stock $A$ to the parent family in the unit. (Recall that $A$ consists of the inheritance from the parents' parents plus the life-cycle saving carried by the parents from age $T$ to $T+1$.) Assigning the descendant family initial assets 0 , consumption and earnings profiles determine asset profiles for the parent and descendant families separately. By construction, the sum of assets within the unit are nonnegative at each age. The is not true, however, for the asset profiles of the parent and child families viewed individually. Whenever the descendant family's assets turn negative, we make, and record, a "lifetime transfer" to it from the parent family just sufficient to keep its assets zero. The transfer is permanent. Similarly, when the parent family's assets would otherwise become negative, we make and record a "lifetime transfer" from the descendant. At the close of age $T$, residual assets from both parties in the unit combine to form $A^{\prime}$; the portion from the older family in the unit constitutes Tablc II's "bequest."

With realistic wealth ratios, the table's lifetime-transfer flows are about equal to bequest flows. As a percentage of GNP the former are far larger than the survey-based figure of 0.025 reported by Cox [9] and Kurz [19]. The empirical figure may be subject to error - see the remarks in Cox $[9$, p. 521]; nevertheless, our model's transfers between families seem very large.

\section{Conclusions}

This paper develops a model which can encompass both life-cycle and dynastic savings. The framework is parsimonious in the sense that no parameters are needed beyond what the life-cycle portion of the model requires. As stated, there is an interpretation of the model that includes marital links between family lines.

Although all family lines have the same preference orderings and draw their earnings' abilities from the same distribution, the stationary equilibrium contains, at least for high enough interest rates, families facing different time horizons until liquidity constraints next bind in their dynasties. The equilibrium determines the cross-sectional frequency distribution associated with the horizon calegories.

Several implications of the analysis at this point are:

(i) Conventional life-cycle models have great difficulty explaining practical aggregate wealth-to-GNP ratios (especially in the presence of technological change, children, and social security), but Proposition 3 shows that this paper's model can easily support high ratios. Section 3's numerical examples confirm this. 
(ii) This paper's framework yields wealth supply curves which are not perfectly interest elastic. (In life-cycle models, the same is true; in the simplest representative agent models it is not.) Although Proposition 3 shows that the supply is asymptotically flat, Section 3's simulations do not seem to support perfect elasticity as a good approximation for applications.

(iii) The analysis provides a reason for expecting a higher frequency of binding lifetime liquidity constraints among low-resource families. Section 3's simulations point to a significant fraction of families being subject to binding liquidity constraints-hence, in effect, to short planning horizons.

(iv) Lifetime constraints, life-cycle saving, and altruism interact. Proposition 4 shows that including lifetime liquidity constraints in our model will, cet. par., increase average intergenerational transfers and wealth accumulation. Section 3's examples bear this out.

While Section 3's simulations are consistent with empirical observations in several very important respects, problems at this point include the large volume of inter vivos transfer activity and the relatively low incidence of binding lifetime liquidity constraints. More sophisticated treatment of lifetime earnings and family composition profiles might help. Another possibility would be to incorporate a positive degree of heritability of earnings abilities. A more elaborate step would be to reduce the intensity of altruism.

Empirical work and qualitative and, increasingly, quantitative policy analyses have made extensive use of life-cycle and representative agent models separately. This paper attempts to show that, at least for steadystate equilibria, a framework incorporating elements from both models, plus lifetime liquidity constraints and earnings heterogeneity, is a feasible alternative. Although preliminary simulations do not agree precisely with empirical observations in every dimension, several important drawbacks, and severe implications, of simpler specifications disappear in the expanded framework.

\section{APPENDIX}

This appendix proves Propositions 1-5. In all cases, "increasing" should be distinguished from "strictly increasing," and "concave" from "strictly concave." $\mu(\cdot)$ is the Lebesgue measure.

\section{Proof of Proposition 1}

Lemma 1 below proves part (iii). We establish parts (i)-(ii) using the general line of reasoning of Lucas and Stokey [32, Chap. 9].

Consider the case with $\beta<0$. Then $v(\cdot) \leqslant 0$. Replacing $v(\cdot)$ in (12) and 
(13) with $\max \left\{v\left(A, A^{\prime}, Z, Z^{\prime} ; r\right), v(0,0,0,0 ; r)\right\}$, we have a bounded problem. Optimizing behavior will render the preceding change irrelevant in terms of $V(\cdot)$ and $\Psi(\cdot)$. Stokey and Lucas [32, Theorems 9.2, 9.6-9.10] apply to the modified problems. Thus, (i)-(ii) hold and $V\left(A, Z, Z^{\prime} ; r\right)$ is concave in $A$.

Suppose $\beta>0$. Then $v(\cdot) \geqslant 0$. Let $V^{U}(\cdot)$ be as in the text. Since the text shows that $V^{U}(A ; r)<\infty$ any $A,[32$, Theorem 9.2] proves that any solution to (13) bounded above by $V^{U}(\cdot)$ gives the optimized value for (12). Define the operator $T$ as in [32, Theorem 9.6]. Let $V^{0}\left(A, Z . Z^{\prime} ; r\right)=$ $v\left(A, 0, Z, Z^{\prime} ; r\right)$ and $V^{n+1}=T\left(V^{n}\right)$ all $n=0,2, \ldots$. Then the sequence of functions $V^{n}$ is monotone nondecreasing and bounded above by $V^{U}$. Hence it has a limit, say, $V^{*}\left(A, Z, Z^{\prime} ; r\right) \leqslant V^{U}(A ; r)$. Standard procedures-see, for example, Laitner [20, Proposition 1]-show $V^{*}(\cdot)$ solves (13). Since the convergence above is uniform, $V^{*}(\cdot)$ is continuous. As in [32, Lemma 9.5], $V^{*}(\cdot)$ is concave and nondccreasing in $A$; thus, the continuity and strict concavity of $v(\cdot)$ imply a unique, single-valued $\Psi(\cdot)$ exists. [32, Theorem 3.6] establishes the continuity of $\Psi(\cdot)$.

Since $V(\cdot)$ is concave in $A$, the right-hand side of (13) shows that $\Psi(\cdot)$ is increasing in $(A, Z)$.

LEMMA 1. If $r \in\left[0, r^{*}\right)$, there is $A^{U}(r)<\infty$ such that $A>A^{U}(r)$ implies $\Psi\left(A, Z, Z^{\prime} ; r\right)<A$ and $A \leqslant A^{U}(r)$ implies $\Psi\left(A, Z, Z^{\prime} ; r\right) \leqslant A^{U}(r)$.

Proof. Fix any $r \in\left[0, r^{*}\right)$.

Step 1 . Suppose at first that lifetime liquidity constraints never bind. Let $c(r) \equiv[\Delta \cdot \Gamma \cdot \rho(r)]^{\sigma}$. Then Laitner [20, Proposition 4] shows that

$$
\begin{gathered}
\Psi\left(A, Z, Z^{\prime} ; r\right) \leqslant \max \left\{0, c(r) \cdot\left[A+Y\left(Z, Z^{\prime} ; r\right)\right]\right\} \\
\text { if } c(r)<1, c(r)<\rho(r) .
\end{gathered}
$$

But,

$$
c(r)<1 \Leftrightarrow \frac{1}{1+\delta} \cdot(1+\gamma)^{\beta} \cdot \frac{1+r}{1+\gamma}<1 \Leftrightarrow r<r^{*} .
$$

So, $c(r)<1$. The preceding also shows $c(r)<\rho(r)$ if $r \geqslant \gamma$. In general,

$$
c(r)<\rho(r) \Leftrightarrow \frac{(1+\gamma)^{\beta}}{1+\delta} \cdot \frac{1+r}{1+\gamma}<\left[\frac{1+r}{1+\gamma}\right]^{1-\beta} \Leftrightarrow \frac{(1+r)^{\beta}}{1+\delta}<1 .
$$

Thus, $r<\gamma$ and $\Delta \cdot \Gamma<1$ imply $c(r)<\rho(r)$ as well. Hence the conditions of (A1) are met. 
Setting $A^{*} \equiv c(r) \cdot Y(1,1 ; r) /(1-c(r))$,

$$
\begin{aligned}
A \leqslant A^{*} \Rightarrow & \Psi\left(A, Z, Z^{\prime} ; r\right) \leqslant \Psi\left(A^{*}, Z, Z^{\prime} ; r\right) \\
& \leqslant c(r) \cdot\left[A^{*}+Y(1,1 ; r)\right]=A^{*}, \\
A>A^{*} \Rightarrow & \Psi\left(A, Z, Z^{\prime} ; r\right) \leqslant c(r) \cdot\left[A-A^{*}+A^{*}+Y(1,1 ; r)\right] \\
& =c(r) \cdot\left[A-A^{*}\right]+A^{*}<A .
\end{aligned}
$$

Step 2. Create a new version of (7) with $\bar{l}(\cdot)$ in place of $l(\cdot)$ and

$$
\bar{l}(s, Z)= \begin{cases}l(s, Z), & \text { if } s=1 ; \\ 0, & \text { otherwise. }\end{cases}
$$

Let $\bar{v}(\cdot)$ be the new version of $v(\cdot), \bar{V}(\cdot)$ the new version of $V(\cdot)$, and $\bar{\Psi}(\cdot)$ the new version of $\Psi(\cdot)$. It is easy to see in (7) that lifetime liquidity constraints never bind for $\bar{v}(\cdot)$. So, replacing $A^{*}$ above with $A^{*} \equiv c(r) \cdot \bar{Y}(1,1 ; r) /(1-c(r)),(A 2)-(A 3)$ hold.

Step 3. In (7), if $B=0$, there exists $A^{* *}<\infty$ such that $A \geqslant A^{* *}$ implies $a(s) \geqslant 0$ does not bind $s=1, \ldots, T$. The same then follows for $A \geqslant A^{* *}$ and any feasible $B \geqslant 0$.

The changes of Step 2, provided total lifetime resources in the present problem (7) are left unchanged and provided none of the constraints $a(s) \geqslant 0$ bind in the present (7), would increase bequests (or leave them unchanged). Define

$$
\eta(r) \equiv Y\left(Z, Z^{\prime} ; r\right)-\bar{l}(1, Z)
$$

Then for $A \geqslant A^{* *}, \Psi\left(A, Z, Z^{\prime} ; r\right) \leqslant \bar{\Psi}\left(A+\eta(r), Z, Z^{\prime} ; r\right)$. Proposition 1 shows that $\Psi(\cdot)$ and $\bar{\Psi}(\cdot)$ are increasing in $A$. Define

$$
A^{* * *} \equiv c(r) \cdot \frac{\eta(r)+\bar{Y}(1,1 ; r)}{1-c(r)} .
$$

Let $A^{U} \equiv \max \left\{A^{*}, A^{* *}, A^{* * *}\right\}$. Then Step 1 shows

$$
\begin{aligned}
A \leqslant A^{U} \Rightarrow & \Psi\left(A, Z, Z^{\prime} ; r\right) \leqslant \Psi\left(A^{U}, Z, Z^{\prime} ; r\right) \\
& \leqslant \bar{\Psi}\left(A^{U}+\eta(r), Z, Z^{\prime} ; r\right) \\
& \leqslant c(r) \cdot\left[A^{U}+\eta(r)+\bar{Y}(1,1 ; r)\right] \\
& =c(r) \cdot\left[A^{U}-A^{* * *}\right]+A^{* * *} \leqslant A^{U}, \\
A>A^{U} \Rightarrow & \Psi\left(A, Z, Z^{\prime} ; r\right) \leqslant \bar{\Psi}\left(A+\eta(r), Z, Z^{\prime} ; r\right) \\
& \leqslant c(r) \cdot\left[A-A^{* * *}\right]+A^{* * *}<A .
\end{aligned}
$$




\section{Proof of Proposition 2}

Part (i) follows from Proposition 1 and Stokey and Lucas [32, Theorem 8.9]; their Theorem 8.5 shows that $\Phi^{n}(\cdot)$ is well defined.

Parts (ii)-(iii) involve verifying that Condition $\mathbf{M}$ of Stokey and Lucas holds, so that their Theorem 11.12 applies. Condition $\mathrm{M}$ is established by showing that there exists $\varepsilon>0$ and integer $N$ such that for any set $\mathscr{F}$ with complement $\mathscr{F}^{c}$ we have

$$
\Phi^{N}(x, \mathscr{F} ; r) \geqslant \varepsilon \quad \text { or } \quad \Phi^{N}\left(x, \mathscr{F}^{c} ; r\right) \geqslant \varepsilon \quad \text { all } x .
$$

Lemma 4 below covers a degenerate case; Lemma 6 establishes $M$ for all other instances.

Lemma 2. Let $r \in\left[0, r^{*}\right)$. Let $\psi(A) \equiv \Psi(A, 0,0)$. Then $\psi(\cdot)$ has a unique fixed point $A^{\mathrm{FP}}$ on $[0, \infty)$. We have $A^{\mathrm{FP}}=\psi(0)<A^{U}$.

Proof. Lemma 1 shows that there is no fixed point above $A^{U}$ and that $\psi:\left[0, A^{U}\right] \rightarrow\left[0, A^{U}\right]$. We have seen $\Psi(\cdot)$, hence $\psi(\cdot)$, is continuous. Thus a fixed point $A^{\mathrm{FP}}$ exists in $\left[0, A^{U}\right]$.

Let $C_{s}\left(A, Z, Z^{\prime} ; r\right), s=1, \ldots, T$, be utility-maximizing age-s consumption (per equivalent adult) for the normalized version of (7) (defining $v(\cdot)$ ), given $A^{\prime}=\Psi\left(A, Z, Z^{\prime} ; r\right)$. It is single-valued and continuous. Standard arguments show that it is increasing in $\left(A, Z, Z^{\prime}\right)$. First-order conditions for a dynasty require

$$
\frac{\partial u\left(C_{1}\left(A^{\mathrm{FP}}, 0,0 ; r\right), 1\right)}{\partial C} \geqslant H(r) \cdot E\left[\frac{\partial u\left(C_{1}\left(A^{\mathrm{FP}}, 0, \tilde{Z} ; r\right), 1\right)}{\partial C}\right],
$$

where $H(r)=\rho(r) /(1+\gamma)^{1-\beta}$. Note that $r<r^{*}$ implies $H(r)<1$. Since $H(r)<1$ and $C_{1}(\cdot)$ is increasing, the foc above must hold with strict inequality. Since $A^{\mathrm{FP}}=\Psi^{\prime}\left(A^{\mathrm{FP}}, 0,0 ; r\right)$, that implies nonnegativity constraints must bind during the lifetime with $\left(A^{\mathrm{FP}}, 0,0\right)$, or at death. Binding constraints imply $\Psi\left(A^{\mathrm{FP}}, 0,0 ; r\right)=\Psi(A, 0,0 ; r)$ for any $A \leqslant A^{\mathrm{FP}}$. Hence, $A^{\mathrm{FP}}=\psi(0)$-making $A^{\mathrm{FP}}$ unique.

Lemma 3. Let $r \in\left[0, r^{*}\right)$. Let $A^{0} \in\left[0, A^{U}\right]$ and $A^{n+1}=\psi\left(A^{n}\right)$ with $\psi(\cdot)$ as abveve. Then $\lim _{n \rightarrow \infty} A^{n}=A^{\mathrm{FP}}$. If $U$ is any open neighborhood of $\left(A^{\mathrm{FP}}, 0\right)$, there exist integer $N$ and positive $p_{0}$ such that a dynasty starting at $\left(A_{0}, Z_{0}\right) \in \mathscr{S}$ has probability $\geqslant p_{0}$ of reaching $\left(A_{N}, Z_{N}\right) \in U$.

Proof. As above, the first-order condition

$$
\frac{\partial u\left(C_{1}\left(A^{n}, 0,0 ; r\right), 1\right)}{\partial C} \geqslant H(r) \cdot E\left[\frac{\partial u\left(C_{1}\left(A^{n+1}, 0, \tilde{Z} ; r\right), 1\right)}{\partial C}\right] .
$$


with $H(r)<1$, must hold with strict inequality if $A^{n+1} \geqslant A^{n}$. The preceding proof then implies $A^{n+1}=A^{\mathrm{FP}}$. So, $A^{n+s}=A^{\mathrm{FP}}$ all $s>1$. Otherwise $A^{n+1}<A^{n}$. Since $A^{n} \geqslant 0$, if that continues, $A^{n} \downarrow \bar{A}$. Then $\bar{A}=\lim \psi\left(A^{n}\right)=$ $\psi(\bar{A})$, with $\bar{A}=A^{\mathrm{FP}}$ according to the preceding lemma.

Let $U$ be an open set containing $\left(A^{\mathrm{FP}}, 0\right)$. Consider a dynasty with $\left(A_{0}, Z_{0}\right)=\left(A^{\mathrm{FP}}, 0\right)$. Generate $A_{i}=\Psi\left(A_{i-1}, Z_{i-1}, Z_{i} ; r\right)$ each $i=1,2, \ldots$. Note $A_{i} \geqslant A^{\mathrm{FP}}$ all $i$. Because $\Psi(\cdot)$ is continuous, the preceding paragraph shows there is finite $N$ and $p_{0}>0$ such that a sequence $Z_{1}, Z_{2}, Z_{3}, \ldots$ of $Z$ 's near zero yielding $\left(A_{N}, Z_{N}\right) \in U$ has probability at least $p_{0}$. Since $\Psi(\cdot)$ is increasing in its first two arguments, the same sequence of $Z_{1}, Z_{2}, \ldots$ yields $\left(A_{N}, Z_{N}\right) \in U$ any $\left(A_{0}, Z_{0}\right) \in \mathscr{P}$.

A special case immediately yields a unique ergodic set and stationary distribution:

LemMa 4. Let $r \in\left[0, r^{*}\right)$. Suppose $\Psi\left(A^{\mathrm{FP}}, Z, Z^{\prime} ; r\right)=A^{\mathrm{FP}}$ for all $Z, Z^{\prime}$. Then $\left\{A^{\mathrm{FP}}\right\} \times \mathscr{Z}$ is the unique ergodic set for $\Phi(\cdot)$. All other states are transitory. The unique stationary distribution assigns zero probability to sets $\mathscr{A} \times \mathscr{B}$ with $A^{\mathrm{FP}} \notin \mathscr{A}$ and probability $\int_{\mathscr{B}} p(Z) \mu(d Z)$ otherwise.

Proof. Let $\Psi\left(A^{\mathrm{FP}}, Z, Z^{\prime} ; r\right)=A^{\mathrm{FP}}$ all $Z, Z^{\prime} \in \mathscr{Z}$. Then clearly $\left\{A^{\mathrm{FP}}\right\} \times \mathscr{Z}$ is an ergodic set and the stationary probabilities are as stated. Lemma 2 shows that $A^{\mathrm{FP}}=\psi(0)$ and that if the dynasty of Fig. 1 has $\left(A, Z, Z^{\prime}\right)=\left(A^{\mathrm{FP}}, 0,0\right)$ at $t+1$, it faces binding asset nonnegativity constraints within $T$ years. First-order conditions and $l(s, Z)>0$ imply there exists an open neighborhood $\mathscr{A}^{0}$ of $A^{\mathrm{FP}}$ such that $\Psi\left(A, Z, Z^{\prime} ; r\right)=$ $\psi(0)$ all $\left(A, Z, Z^{\prime}\right) \in \mathscr{A}^{0} \times\left[0, \frac{1}{2}\right] \times \mathscr{Z}$. Then Lemma 3 shows all states outside of $\left\{A^{\mathrm{FP}}\right\} \times \mathscr{Z}$ are transitory.

For cases other than Lemma 4, we need Lemmas 5-6.

Lemma 5. Fix any $A, Z_{0}$, and $Z_{2}$. Define

$$
f(Z ; r) \equiv \Psi\left(\Psi\left(A, Z_{0}, Z ; r\right), Z, Z_{2} ; r\right) .
$$

Suppose $f(Z ; r)>0, \Delta Z>0$, and $Z+\Delta Z \leqslant 1$. Then there exist positive $\alpha_{1}$ and $\alpha_{2}$, independent of $A, Z_{0}, Z, Z_{2}, \Delta Z$, and $r \in\left[0, r^{*}\right)$ such that

$$
\alpha_{1} \cdot \Delta Z \leqslant f(Z+\Delta Z ; r)-f(Z ; r) \leqslant \alpha_{2} \cdot \Delta Z \text {. }
$$

The upper bound applies even if $f(Z ; r)=0$.

Proof. Think of the dynasty in Fig. 1 with $t=0$. Let $\Psi\left(A, Z_{0}, Z_{1} ; r\right)$ be its transfer at date $T$; let $f\left(Z_{1} ; r\right)$ be its transfer at $2 . T$. Think of an increase $\Delta Z$ in $Z_{1}$. Then dynastic earnings rise between $\zeta_{1} \cdot \Delta Z$ and $2 \cdot \zeta_{2} \cdot \Delta Z$ for times $1, \ldots, 2 \cdot T$. First-order conditions show the transfer at 
$2 \cdot T$ could rise or remain unchanged, but it could not fall. First-order conditions also show that no more than the present value at time $2 . T$ of the entire earnings increase could be bequeathed. This and $\zeta_{2}$ imply $\alpha_{2}$.

A larger $Z=Z^{1}$ increases dynastic earnings by at least $\zeta_{1} \cdot \Delta Z$ for each time $1, \ldots, 2 \cdot T$. If the transfer at $2 \cdot T$ remained unchanged, first-order conditions put a definite lower bound on the increase in normalized consumption (see Lemma 2) $C_{2} \cdot T$. When $f(Z ; r)>0$,

$$
\frac{\partial u\left(C_{2 \cdot T}, 2 \cdot T\right)}{\partial C}=\frac{1+r}{1+\delta} \cdot \frac{1}{(1+\gamma)^{\beta-1}} \cdot E\left[\frac{\partial u\left(\tilde{C}_{2 \cdot T+1}, 2 \cdot T+1\right)}{\partial C}\right] .
$$

Thus the transfer at $2 \cdot T$ must rise for $\Delta Z>0$. The rise will be smallest if lifetime constraints route the entire increase in the transfer to $C_{2 \cdot T+1}$. Even in that case, (A4) implies a positive $x_{1}$.

LemMa 6. Let $r \in\left[0, r^{*}\right)$. Suppose $\Psi\left(A^{\mathrm{FP}}, Z, Z^{\prime} ; r\right) \neq A^{\mathrm{FP}}$ some $Z, Z^{\prime} \in \mathscr{Z}$. Then $\Phi(\cdot)$ satisfies the conditions of Stokey and Lucas [32, Theorem 11.12].

Proof. Recall $p(Z) \in\left[p^{L}, p^{U}\right] \subset(0, \infty)$ all $Z \in \mathscr{Z}$. Fix any $r \in\left[0, r^{*}\right)$.

Step 1. We first show

$$
\Psi\left(\Psi\left(A^{\mathrm{FP}}, 0, Z ; r\right), Z, Z^{\prime} ; r\right)>0 \quad \text { for some } Z, Z^{\prime} \in \mathscr{Z} .
$$

If $A^{\mathrm{FP}}>0$, set $Z=Z^{\prime}=0$. Then Lemma 2 implies

$$
\begin{aligned}
& \Psi\left(\Psi\left(A^{\mathrm{FP}}, 0, Z ; r\right), Z, Z^{\prime} ; r\right)=\Psi\left(\Psi_{\left.\left(A^{\mathrm{FP}}, 0,0 ; r\right), 0,0 ; r\right)}\right. \\
& =\Psi\left(A^{\mathrm{FP}}, 0,0 ; r\right)=A^{\mathrm{FP}}>0 .
\end{aligned}
$$

If $A^{\mathrm{FP}}=0$, since $\Psi(\cdot) \geqslant 0$, this lemma's statement implies $\Psi\left(A^{\mathrm{FP}}, Z, Z^{\prime} ; r\right)$ $>0$ for some $Z, Z^{\prime}$. Then, using the monotonicity established in Proposition 1 and $\Psi(\cdot) \geqslant 0$,

$$
\Psi\left(\Psi\left(A^{\mathrm{FP}}, 0, Z ; r\right), Z, Z^{\prime} ; r\right) \geqslant \Psi\left(0, Z, Z^{\prime} ; r\right)=\Psi\left(A^{\mathrm{FP}}, Z, Z^{\prime} ; r\right)>0 .
$$

Step 2. We establish Stokey and Lucas' [32] Condition M. The continuity of $\Psi^{\prime}(\cdot)$ and (A5) imply there exist open intervals $\mathscr{A}^{0}, \mathscr{U}^{0}, \mathscr{U}^{1}$, and $\mathscr{U}^{2}$ such that $A^{\mathrm{FP}} \in \mathscr{A}^{0}, 0 \in \mathscr{U}^{0}$, and

$$
\left(A^{0}, Z^{0}, Z^{1}, Z^{2}\right) \in \mathscr{A}^{0} \times \mathscr{U}^{0} \times \mathscr{U}^{1} \times \mathscr{U}^{2} \Rightarrow \Psi\left(\Psi\left(A^{0}, Z^{0}, Z^{1} ; r\right), Z^{1}, Z^{2} ; r\right)>0 .
$$

Define $\mathscr{W}^{0} \equiv \mathscr{A}^{0} \times \mathscr{U}^{0}$. Let

$$
\mathscr{R}\left(x, Z_{2}\right) \equiv\left\{\Psi\left(\Psi\left(x, Z_{1} ; r\right), Z_{1}, Z_{2} ; r\right): Z_{1} \in \mathscr{U}^{1}\right\}
$$


For $x \in \mathscr{W}^{0}$ and $Z_{2} \in \mathscr{U}^{2}$, Lemma 5 implies that

$$
\mu\left(\mathscr{R}\left(x, Z_{2}\right)\right) \geqslant \alpha_{1} \cdot \mu\left(\mathscr{U}^{1}\right)>0
$$

and that $\mathscr{R}\left(x, Z_{2}\right)$ is an interval. Using the continuity of $\Psi(\cdot)$, there exist nonempty open $\mathscr{W}^{00} \subset \mathscr{W}^{0}$, open $\mathscr{U}^{22} \subset \mathscr{U}^{2}$, and open $\mathscr{R}^{11}$ such that

$$
\mathscr{R}^{11} \subseteq \mathscr{R}\left(x, Z_{2}\right) \quad \text { for all } \quad x \in \mathscr{W}^{00}, Z_{2} \in \mathscr{U}^{22} .
$$

Define

$$
G\left(x, Z_{2}, \mathscr{X} ; r\right)=\left\{Z_{1}:\left(\Psi\left(\Psi\left(x, Z_{1} ; r\right), Z_{1}, Z_{2} ; r\right), Z_{2}\right) \in \mathscr{X}\right\} .
$$

For $x \in \mathscr{W}^{00}$ and $Z_{2} \in \mathscr{U}^{22}$, Lemma 5 implies

$$
\mu\left(G\left(x, Z_{2}, \mathscr{Q}\right) ; r\right) \geqslant \frac{\mu(\mathscr{Q})}{\alpha_{2}} \quad \text { for any } \quad \mathscr{Q} \subseteq \mathscr{R}^{11} .
$$

So, for $x \in \mathscr{W}^{00}$ and $\mathscr{X} \subseteq \mathscr{R}^{11} \times \mathscr{U}^{22}$,

$$
\begin{aligned}
\Phi^{2}(x, \mathscr{X} ; r) & =\int_{\mathbb{H}^{22}} \int_{G\left(x, Z_{2}, \mathscr{X} ; r\right)} p\left(Z_{1}\right) \mu\left(d Z_{1}\right) p\left(Z_{2}\right) \mu\left(d Z_{2}\right) \\
& \geqslant\left[p^{L}\right]^{2} \cdot \int_{\mathbb{H}^{22}} \int_{G\left(x, Z_{2}, \mathscr{X} ; r\right)} \mu\left(d Z_{1}\right) \mu\left(d Z_{2}\right) \\
& \geqslant \frac{\left[p^{L}\right]^{2}}{\alpha_{2}} \cdot \int_{\mathscr{H}^{22}} \int_{\left\{Z_{1}:\left(Z_{1}, Z_{2}\right) \in \mathscr{X}\right\}} \mu\left(d Z_{1}\right) \mu\left(d Z_{2}\right) \\
& \geqslant \frac{\left[p^{L}\right]^{2}}{\alpha_{2}} \cdot \mu \times \mu(\mathscr{X}) .
\end{aligned}
$$

Lemma 3 implies that from any starting point $x \in \mathscr{S}$, a dynasty has probability $\geqslant p_{0}>0$ of reaching $\mathscr{W}^{00}$ after $N$ periods. Thus, for any $x \in \mathscr{S}$ and $\mathscr{X} \subseteq \mathscr{R}^{11} \times \mathscr{U}^{22}$,

$$
\begin{aligned}
\Phi^{N+2}(x, \mathscr{X} ; r) & \geqslant \int_{\mathscr{W} \infty} \Phi^{2}\left(x^{\prime}, \mathscr{X} ; r\right) \cdot \Phi^{N}\left(x, d x^{\prime} ; r\right) \\
& \geqslant \frac{\left[p^{L}\right]^{2}}{\alpha_{2}} \cdot \mu \times \mu(\mathscr{X}) \cdot \int_{\mathscr{W}-\infty 0} \Phi^{N}\left(x, d x^{\prime} ; r\right) \\
& \geqslant \frac{\left[p^{L}\right]^{2}}{\alpha_{2}} \cdot \mu \times \mu(\mathscr{X}) \cdot p_{0} .
\end{aligned}
$$

Let $\varepsilon$ be half the final magnitude in (A6). Consider any set $\mathscr{F}$ in $\mathscr{S}$ and its complement $\mathscr{F}^{c}$. At least half the area of $\mathscr{X}$ must lie in $\mathscr{F}$ or $\mathscr{F}^{c}$. In the former case, for example, $\Phi^{N+2}(x, \mathscr{F} ; r) \geqslant \varepsilon$ all $x \in \mathscr{S}$. 


\section{Proof of Proposition 3}

Provided $r<r^{*}$, the stationary distribution of $A$ is bounded-hence so is $\Upsilon(r)$. Let $A^{\mathrm{FP}}$ be as in Lemma 2. The Lemma's proof shows nonnegativity constraints bind between $t+1$ and $t+T+1$ for the dynasty of Fig. 1 if it begins period $t+1$ having $\left(A_{i}, Z_{i}, Z_{i+1}\right)=\left(A^{\mathrm{FP}}, 0,0\right)$. Thus there exist open sets $\mathscr{A}$ containing $A^{\mathrm{FP}}$ and $\mathscr{U}$ containing 0 such that nonnegativity constraints bind on the dynasty between $t+1$ and $t+T+1$ if $\left(A_{i}, Z_{i}, Z_{i+1}\right) \in \mathscr{A} \times \mathscr{U} \times \mathscr{U}$. The last part of Lemma 3 then establishes (ii).

Following Stokey and Lucas [32, p. 237], note that for

$$
g: \mathfrak{R}^{2} \rightarrow \mathfrak{R}^{2} \quad \text { and } \quad \tilde{g}\left(x, z^{\prime} ; r\right) \equiv g\left(\Psi\left(x, z^{\prime} ; r\right), z^{\prime}\right) \cdot p\left(z^{\prime}\right),
$$

we have

$$
\int_{\mathscr{S}} g\left(x^{\prime}\right) \cdot \Phi\left(x, d x^{\prime} ; r\right)=\int_{\mathscr{Z}} \tilde{g}\left(x, z^{\prime} ; r\right) \mu\left(d z^{\prime}\right)
$$

If $g(\cdot)$ is continuous, $\tilde{g}(\cdot)$ is too. In that case, the Lebesgue dominated convergence theorem shows that

$$
\int_{\mathscr{I}} g^{*}\left(x_{n}, z^{\prime} ; r_{n}\right) \mu\left(d z^{\prime}\right) \rightarrow \int_{\mathscr{Z}} g^{*}\left(x, z^{\prime} ; r\right) \mu\left(d z^{\prime}\right) .
$$

Hence $\Phi\left(x_{n}, \cdot ; r_{n}\right)$ converges weakly to $\Phi(x, \cdot ; r)$. [32, Theorem 12.13] then establishes the continuity of $Y(\cdot)$.

The last task is to show $\lim _{r \uparrow r^{*}} Y(r)=\infty$. This will follow if we can show the mean of the stationary distribution of bequests converges to $\infty$ as $r \uparrow r^{*}$.

Modify (7) to drop the lifetime nonnegativity constraint on asset holdings. The normalized version of (7) then has a closed form solution $v^{*}(\cdot)$ with

$$
v^{*}\left(A, A^{\prime}, Z, Z^{\prime} ; r\right)=\frac{v_{0}(r)}{\beta} \cdot\left[A+Y\left(Z, Z^{\prime} ; r\right)-\frac{A^{\prime}}{\rho(r)}\right]^{\beta},
$$

where $v_{0}(r)$ is a known function. Define $V^{* n}(\cdot)$ for the new problem as in the proof of Proposition 1. Note the convergence of the corresponding policy functions $\Psi^{* n}(\cdot)$ - as in Stokey and Lucas [32, Theorem 9.9]. Letting $V^{n}(\cdot)$ and $\Psi^{n}(\cdot)$ apply with lifetime constraints, it is not difficult to see that

$$
\Psi^{n}\left(A, Z, Z^{\prime} ; r\right) \geqslant \Psi^{* n}\left(A, Z, Z^{\prime} ; r\right) \quad \text { for all } n=1,2, \ldots .
$$

In fact, we can generate even a lower bound $\Psi^{* * n}(\cdot)$ for each $n$ : having written first-order conditions determining $\Psi^{* n}(\cdot)$, take the expected value 
operator inside the marginal utility expression-using Jensen's inequality. In solving the first-order conditions, drop the nonnegativity constraint $A^{\prime} \geqslant 0$. (This does not imply an unbounded problem; in the $n$th period, consumption must equal current earnings and assets on hand.) We can derive a closed-form solution for the limit, say, $\Psi^{* *}(\cdot)$. Let $H(r)<1$ be as in Lemma 2. Note: $\Delta \cdot \Gamma<1$ and the definition of $r^{*}$ show that $\rho(r)>1$ for $r$ near $r^{*}$. Then if $y_{1}(Z ; r) \equiv \sum_{s=1}^{T}(1+\gamma)^{s-1} \cdot(1+r)^{1-s} \cdot l(s, Z)$ and $y_{2}(Z ; r) \equiv \sum_{s=1}^{T}(1+\gamma)^{s-1} \cdot(1+r)^{1-s} \cdot l(s+T, Z)$,

$$
\begin{aligned}
\Psi^{* *}\left(A, Z, Z^{\prime} ; r\right)= & h \cdot\left[A+y_{2}(Z ; r)+y_{1}\left(Z^{\prime} ; r\right)\right] \\
& +\frac{H(r)-\rho(r)}{\rho(r)} \cdot y_{2}\left(Z^{\prime} ; r\right) \\
& -\frac{H(r)-\rho(r)}{(1-\rho(r))} \cdot E\left[y_{1}(\tilde{Z} ; r)+y_{2}(\tilde{Z} ; r) / \rho(r)\right] .
\end{aligned}
$$

In fact, since Jensen's inequality is strict, given our assumptions about $\tilde{Z}$,

$$
\Psi\left(A, Z, Z^{\prime} ; r\right) \geqslant \Psi^{* *}\left(A, Z, Z^{\prime} ; r\right)+\varepsilon\left(A, Z, Z^{\prime} ; r\right),
$$

where $\varepsilon(\cdot)$ is strictly positive and continuous.

Suppose the mean of the stationary distribution of $A$ does not diverge as $r \uparrow r^{*}$. Then we can find a sequence $r_{n} \uparrow r^{*}$ and a finite bound $A^{\max }$ for the corresponding stationary distribution means, say, $\bar{A}_{n}$. Because $0 \leqslant \bar{A}_{n} \leqslant A^{\text {max }}$, at least half of the probability weight for $\widetilde{A}_{n}$ must fall in $\left[0,2 \cdot A^{\max }\right]$. For a stationary $\left(\tilde{A}_{n}, \widetilde{Z}\right)$,

$$
\tilde{A}_{n} \sim \Psi\left(\tilde{A}_{n}, \tilde{Z}, \tilde{Z}^{\prime} ; r_{n}\right)
$$

Using (A10),

$$
\bar{A}_{n}=E\left[\Psi\left(\tilde{A}_{n}, \tilde{Z}, \tilde{Z}^{\prime} ; r_{n}\right)\right] \geqslant E\left[\Psi^{* *}\left(\tilde{A}_{n}, \tilde{Z}, \tilde{Z}^{\prime} ; r_{n}\right)\right]+E\left[\varepsilon\left(\tilde{A}_{n}, \tilde{Z}, \tilde{Z}^{\prime} ; r_{n}\right)\right] .
$$

If half the probability weight for $\tilde{A}_{n}$ each $n$ falls in $\left[0,2 \cdot A^{\max }\right]$, there exists $\tau>0$ with $E\left[\varepsilon\left(\tilde{A}_{n}, \tilde{Z}, \tilde{Z}^{\prime} ; r_{n}\right)\right] \geqslant \tau$ all $n$. Using (A9), for $r=r_{n}$,

$$
\Psi^{* *}\left(A, Z, Z^{\prime} ; r_{n}\right)=H\left(r_{n}\right) \cdot A+\operatorname{terms}+\varepsilon\left(A, Z, Z^{\prime} ; r_{n}\right),
$$

where the "terms" converge to 0 as $H\left(r_{n}\right) \rightarrow 1$ (i.e., as $r \rightarrow r^{*}$ ). Thus,

$$
\begin{aligned}
\infty & >A^{\max } \geqslant \lim _{n \rightarrow \infty} \bar{A}_{n} \geqslant \lim _{n \rightarrow \infty} \frac{E\left[\varepsilon\left(\tilde{A}_{n}, \tilde{Z}, \tilde{Z}^{\prime} ; r_{n}\right)\right]}{1-H\left(r_{n}\right)} \\
& \geqslant \lim _{r_{n} \uparrow r^{*}} \frac{\tau}{1-H\left(r_{n}\right)}=\infty,
\end{aligned}
$$

a contradiction. So, $\lim _{r \uparrow r^{*}} \Upsilon(r)=\infty$. 


\section{Proof of Proposition 4}

Use Stokey and Lucas' definition of monotonicity for measures. Let $g: \Re^{2} \rightarrow \Re^{2}$ be increasing. Define $\tilde{g}(\cdot)$ as in (A7) using $\Psi(\cdot)$, and $\tilde{g}^{*}(\cdot)$ using $\Psi^{*}(\cdot)$. Then (A7) and (19) imply $\Phi(x, \cdot ; r) \geqslant \Phi^{*}(x, \cdot ; r)$. Since $\Psi\left(x, Z^{\prime} ; r\right)$ is increasing in $x$ (see Proposition 1), (A7) shows that $x_{1} \geqslant x_{0}$ implies $\Phi\left(x_{1}, \cdot ; r\right) \geqslant \Phi\left(x_{0}, \cdot ; r\right)$. Let $g(\cdot)$ be as above. Let $\Phi^{n}(\cdot)$ be the iterated transition function constructed from $\Psi(\cdot)$; let $\Phi^{* n}(\cdot)$ be the same for $\Psi^{*}(\cdot)$. Then Exercise 12.11 of Stokey and Lucas shows that

$$
\begin{aligned}
& \iint g\left(x^{\prime \prime}\right) \cdot \Phi\left(x^{\prime}, d x^{\prime \prime}\right) \Phi\left(x, d x^{\prime}\right) \\
& \quad \geqslant \iint g\left(x^{\prime \prime}\right) \cdot \Phi\left(x^{\prime}, d x^{\prime \prime}\right) \Phi^{*}\left(x, d x^{\prime}\right) \\
& \quad \geqslant \iint g\left(x^{\prime \prime}\right) \cdot \Phi^{*}\left(x^{\prime} d x^{\prime \prime}\right) \Phi^{*}\left(x, d x^{\prime}\right) .
\end{aligned}
$$

Similarly, induction shows that $\Phi^{n}(x, \cdot ; r) \geqslant \Phi^{* n}(x, \cdot ; r)$ for all $n=1,2, \ldots$. Part (i) then follows from part (iii) of Proposition 2.

Look at (16). Since $\Psi(\cdot)$ is increasing in $(A, Z), a(\cdot)$ is too-recall Mariger's [27] diagrams. The preceding paragraph shows $\phi(\cdot ; r) \geqslant \phi^{*}(\cdot ; r)$. This and (19) then establish part (ii).

\section{Proof of Proposition 5}

Using the notation from previous proofs, when $l(s, Z)=Z \cdot l(s, 1)$ and $\lambda \geqslant 1$,

$$
\Psi^{k}\left(\lambda \cdot A, \lambda \cdot Z, \lambda \cdot Z^{\prime} ; r\right)>\lambda \cdot \Psi^{k}\left(A, Z, Z^{\prime} ; r\right) \quad \text { for all } k
$$

(i.e., if all future $Z$ 's were multiplied by $\lambda, \Psi^{k}\left(A, Z, Z^{\prime} ; r\right)$ would be too). Part (i) follows since $\lim _{k \rightarrow \infty} \Psi^{k}\left(A, Z, Z^{\prime} ; r\right)=\Psi\left(A, Z, Z^{\prime} ; r\right)$. Part (ii) then follows from Mariger's [27] diagrams.

\section{REFERENCES}

1. D. Altig and S. J. Davis, Government debt, redistributive fiscal policies, and the interaction between borrowing constraints and intergenerational altruism, J. Monet. Econ. 24 (1989), 3-30.

2. A. J. Auerbach and L. J. Kotlikoff, "Dynamic Fiscal Policy," Cambridge Univ. Press, Cambridge, UK, 1987.

3. R. J. Barro, Are government bonds net wealth? J. Polit. Econ. 82 (1974), 1095-1117. 
4. R. E. Bellman, "Dynamic Programming," Princeton Univ. Press, Princeton, NJ, 1957.

5. B. D. Bernheim and K. Bagwell, Is everything neutral? J. Polit. Econ. 96 (1988), 308-338.

6. T. BEWLEY, The permanent income hypothesis: A theoretical formulation, J. Econ. Theory 16 (1977), 252-292.

7. W. Brock and L. Mirman, Optimal growth and uncertainty: The discounted case, J. Econ. Theory 4 (1972), 479-513.

8. J. Y. Campaell and N. G. Mankiw, Permanent income, current income, and consumption, J. Bus. Econ. Statist. 8 (1990), 265-280.

9. D. Cox, Motives for private income transfers, J. Polit. Econ. 95 (1987), 508-546.

10. E. F. Denison, "Accounting for Slower Economic Growth: The United States in the 1970s," The Brookings Institution, Washington, DC, 1979.

11. M. D. Dooley and P. Gottschalk, Earnings inequality among males in the United States: Trends and the effect of labor force growth, J. Polit. Econ. 92 (1984), 59-89.

12. M. FeldStEIN, The effects of fiscal policies when incomes are uncertain: A contradiction of Ricardian equivalence, Amer. Econ. Rev. 78 (1988), 14-23.

13. R. E. HALL, Comment, Brookings Pap. Econ. Act. (1986), 51-53.

14. R. E. Hall and F. S. MishKin, The sensitivity of consumption to transitory income: Estimates from panel data on households, Econometrica 50 (1982), 461-482.

15. H. HORI AND S. KANAYA, Utility functional with nonpaternalistic intergenerational altruism, J. Econ. Theory 49 (1989), 241-265.

16. D. W. Katzner, "Static Demand Theory," Macmillan Co., New York, 1970.

17. M. Kimball, Making sense of Two-sided altruism, J. Monet. Econ. 20 (1987), 301-326.

18. L. J. KotLIKofF AND L. H. SUmmfrs, The role of intergenerational transfers in aggregate capital accumulation, J. Polit. Econ. 89 (1981), 706-732.

19. M. KURZ, Capital accumulation and the characteristics of private intergenerational transfers, Economica 51 (1984), 1-22.

20. J. LAITNER, Household bequest behaviour and the national distribution of wealth, Rev. Econ. Stud. 46 (1979), 467-483.

21. J. LAITNER, Bequests, gifts, and social security, Rev. Econ. Stud. 55 (1988), 275-300.

22. J. Laitner, Modeling marital connections among family lines, J. Polit. Econ. 99 (1991), 1123-1141.

23. J. LAITNER, Long-run equilibria with borrowing constraints and intergenerational altruism, J. Econ. Dynam. Control, to appear.

24. A. LindBeck AND J. W. Weibull, Altruism and time consistency: The economics of fait accompli, J. Polit. Econ. 96 (1988), 1165-1182.

25. G. C. LouRY, Intergenerational transfers and the distribution of earnings, Econometrica 49 (1981), 843-867.

26. R. P. MARIGer, "Consumption Behavior and the Effects of Government Fiscal Policies," Harvard Univ. Press, Cambridge, MA, 1986.

27. R. P. MARIGER, A life-cycle consumption model with liquidity constraints: Theory and empirical results, Econometrica 55 (1987), 533-558.

28. P. L. MenchiK AND M. David, Income distribution, lifetime savings, and bequests, Amer. Econ. Rev. 73 (1983), 672-690.

29. J. Musgrave, Fixed reproducible tangible wealth in the United States: Revised estimates, Surv. Curr. Bus. 66 (1986), 51-75.

30. J. SEATER, The market value of outstanding government debt: 1919-1975, J. Monet. Econ. $8(1981), 85-101$.

31. J. Schechtman, An income fluctuation problem, $J$. Econ. Theory 12 (1976), 218-241.

32. N. L. Stokey and R. E. LuCas, JR., "Recursive Methods in Economic Dynamics," Harvard Univ. Press, Cambridge, MA, 1989. 
33. L. Thurow, The optimal lifetime distribution of consumption expenditures, Amer. Econ. Rev. 59 (1969), 324-330.

34. J. ToBin, Life cycle saving and balanced growth, in "Ten Economic Studies in the Tradition of Irving Fisher" (W. Fellner, Ed.), pp. 231-256, Wiley, New York, 1967.

35. U.S. Department of Commerce, Bureau of the Census, "Statistical Abstract of the United States 1978," U.S Government Printing Office, Washington, DC, 1978.

36. U.S. Department of Health and Human Services, Social Security Administration, Social Security Bulletin, Annual Statistical Supplement, U.S. Government Printing Office, Washington, DC, 1972.

37. U.S. Department of Labor, Bureau of Labor Statistics, Employment und Earnings, U.S. Government Printing Office, Washington, DC, 1972.

38. M. YAARI, A law of large numbers in the theory of consumer's choice under uncertainty, J. Econ. Theory 12 (1976), 202-217.

39. S. Zeldes, Consumption and liquidity constraints: An empirical investigation, J. Polit. Econ. 97 (1989), 305-346. 